\title{
A novel slow-inactivation-specific ion channel modulator attenuates neuropathic pain
}

\author{
Michael E. Hildebrand ${ }^{a}$, Paula L. Smith ${ }^{a}$, Chris Bladen ${ }^{b}$, Cyrus Eduljee $^{a}$, Jennifer Y. Xie ${ }^{c}$, Lina Chen ${ }^{b}$, \\ Molly Fee-Maki ${ }^{a}$, Clint J. Doering ${ }^{b}$, Janette Mezeyova ${ }^{a}$, Yongbao Zhu ${ }^{a}$, Francesco Belardetti ${ }^{a}$, \\ Hassan Pajouhesh ${ }^{a}$, David Parker ${ }^{a}$, Stephen P. Arneric ${ }^{a}$, Manjeet Parmar ${ }^{a}$, Frank Porreca ${ }^{c}$, \\ Elizabeth Tringham ${ }^{\mathrm{a}}$, Gerald W. Zamponi ${ }^{\mathrm{b}}$, Terrance P. Snutch ${ }^{\mathrm{a}, \mathrm{d}, *}$ \\ a Zalicus Pharmaceuticals, 301-2389 Health Sciences Mall, Vancouver, BC, Canada V6T 1Z3 \\ ${ }^{\mathrm{b}}$ Department of Physiology and Pharmacology, University of Calgary, Calgary, AB, Canada T2N 4N1 \\ ${ }^{\mathrm{c}}$ Department of Pharmacology and Anesthesiology, University of Arizona, Tucson, AZ 85724, USA \\ ${ }^{\mathrm{d}}$ Michael Smith Laboratories, University of British Columbia, 2185 East Mall, Vancouver, BC, Canada V6T 174
}

Sponsorships or competing interests that may be relevant to content are disclosed at the end of this article.

\section{A R T I C L E I N F O}

\section{Article history:}

Received 30 July 2010

Received in revised form 8 December 2010

Accepted 20 December 2010

\section{Keywords:}

Sodium channel

Calcium channel

Slow inactivation

Neuropathic pain

Dorsal root ganglia

Dorsal horn

\begin{abstract}
A B S T R A C T
Voltage-gated ion channels are implicated in pain sensation and transmission signaling mechanisms within both peripheral nociceptors and the spinal cord. Genetic knockdown and knockout experiments have shown that specific channel isoforms, including $\mathrm{Na}_{\mathrm{V}} 1.7$ and $\mathrm{Na}_{\mathrm{V}} 1.8$ sodium channels and $\mathrm{Ca}_{\mathrm{V}} 3.2$ T-type calcium channels, play distinct pronociceptive roles. We have rationally designed and synthesized a novel small organic compound (Z123212) that modulates both recombinant and native sodium and calcium channel currents by selectively stabilizing channels in their slow-inactivated state. Slow inactivation of voltage-gated channels can function as a brake during periods of neuronal hyperexcitability, and Z123212 was found to reduce the excitability of both peripheral nociceptors and lamina I/II spinal cord neurons in a state-dependent manner. In vivo experiments demonstrate that oral administration of Z123212 is efficacious in reversing thermal hyperalgesia and tactile allodynia in the rat spinal nerve ligation model of neuropathic pain and also produces acute antinociception in the hot-plate test. At therapeutically relevant concentrations, Z123212 did not cause significant motor or cardiovascular adverse effects. Taken together, the state-dependent inhibition of sodium and calcium channels in both the peripheral and central pain signaling pathways may provide a synergistic mechanism toward the development of a novel class of pain therapeutics.
\end{abstract}

(c) 2011 International Association for the Study of Pain. Published by Elsevier B.V. All rights reserved.

\section{Introduction}

Voltage-gated sodium $\left(\mathrm{Na}_{\mathrm{V}}\right)$ and calcium $\left(\mathrm{Ca}_{\mathrm{V}}\right)$ channels are crucially involved in nociceptive signaling pathways, in part by mediating ionic currents that contribute to the excitability of peripheral nociceptors in the dorsal root ganglia (DRG). A specific subtype of T-type $\mathrm{Ca}_{\mathrm{v}}$ channel $\left(\mathrm{Ca}_{\mathrm{V}} 3.2\right)$ is highly expressed in DRG neurons and is involved in the initiation of action potential (AP) firing and the generation of burst firing $[6,19,31,42]$. Both tetrodotoxin (TTX)-sensitive $\mathrm{Na}_{\mathrm{V}} 1.7$ and TTX-resistant $\mathrm{Na}_{\mathrm{V}} 1.8$ channels are also robustly expressed in DRGs and are important for setting the

\footnotetext{
* Corresponding author at: Michael Smith Laboratories, University of British Columbia, 2185 East Mall, Vancouver, BC, Canada V6T 1Z4. Tel.: +1 604822 6968; fax: +1 6048226470 .

E-mail addresses: snutch@msl.ubc.ca, tsnutch@zalicus.com (T.P. Snutch).
}

threshold and upstroke of AP firing, respectively, and further act to influence the frequency and sustainability of firing [10].

Within the spinal cord dorsal horn, second-order neurons in superficial layers (lamina I/II) relay nociceptive-specific signals from peripheral nociceptors to pain-processing regions of the brain. Evidence suggests that a variety of $\mathrm{Na}_{V}$ and $\mathrm{Ca}_{\mathrm{V}}$ channel isoforms are expressed within lamina I/II neurons $[14,42,45]$ and that both $\mathrm{Na}_{\mathrm{V}}$ and $\mathrm{Ca}_{\mathrm{V}}$ channels may increase the excitability of dorsal horn neurons linked to neuropathic and inflammatory pain signaling $[11,14,20]$. Specific $\mathrm{Na}_{\mathrm{v}}$ and $\mathrm{Ca}_{\mathrm{v}}$ isoforms have been shown to play pronociceptive roles; knockout of either $\mathrm{Na}_{\mathrm{V}} 1.7$ or $\mathrm{Na}_{\mathrm{V}} 1.8$ channels or knockdown of $\mathrm{Ca}_{\mathrm{v}} 3.2 \mathrm{~T}$-type channels reduces hyperalgesia and allodynia in animal models of acute and neuropathic pain $[6,25,30]$. In humans, loss-of-function mutations in the $\mathrm{Na}_{\mathrm{V}} 1.7$ channel lead to complete abolition of pain sensation, while gain-of-function $\mathrm{Na}_{\mathrm{V}} 1.7$ mutations cause severe chronic pain syndromes [10]. 
Neuropathic pain results from damage to the peripheral or central nervous system and persists long after the nerve injury has resolved [46]. Pharmaceutical approaches to the management of neuropathic pain are limited, and the continued use of some therapeutics can lead to a variety of adverse events and/or desensitization of drug effects. It has been hypothesized that the increased AP firing and sustained depolarization of neurons associated with neuropathic pain may drive a greater subset of $\mathrm{Na}_{\mathrm{V}}$ and $\mathrm{Ca}_{\mathrm{V}}$ channels into a protective slow-inactivated state in order to dampen neuronal excitability $[4,5,17,44]$. In this regard, blockers selectively targeting the slow-inactivated channel state would be predicted to mitigate off-target effects by preferentially attenuating aberrantly hyperexcitable neurons while largely sparing normally firing neurons and other nonhyperexcited targets.

In the current study, we have designed and characterized a lowmolecular-weight, orally available organic compound (Z123212) that stabilizes the slow-inactivated state of $\mathrm{Na}_{V}$ and $\mathrm{Ca}_{V}$ channels, including TTX-resistant $\mathrm{Na}_{V}$ and T-type $\mathrm{Ca}_{V}$ channels in DRG neurons and TTX-sensitive $\mathrm{Na}_{\mathrm{v}}$ channels in lamina I/II spinal cord neurons. Z123212 potently reduces the excitability of DRGs and lamina I/II neurons and is found to reverse thermal and mechanical hypersensitivity in animal models of acute and neuropathic pain. The identification of compounds such as Z123212 that have potentially synergistic effects by targeting multiple ion channels in components of the peripheral and central nociceptive signaling pathways through a state-dependent mechanism may lead to the development of novel classes of safe and effective pain therapeutics.

\section{Methods}

\subsection{Chemistry}

The synthesis of Z123212 is illustrated in Suppl. Fig. 1. Briefly, ethylenediamine- $N, N$-diacetic acid was cyclized under acidic conditions followed by $N$-tert-butoxycarbonyl (Boc) protection of piperazinone nitrogen. Subsequent coupling with bis-CF3 aniline mediated by $O$-benzotriazol-1-yl- $N, N, N^{\prime}, N^{\prime}$-tetramethyluronium hexafluorophosphate (HATU) in $N, N$-dimethylformamide (DMF) provided the desired intermediate and was followed by deprotection of the Boc group to generate Z123212.

\subsection{HEK 293 cell culture, transfection, and electrophysiology}

Human embryonic kidney cells (HEK 293) were cultured and either stably or transiently transfected with recombinant $\mathrm{Na}_{V}$ and $\mathrm{Ca}_{\mathrm{V}}$ channel genes as previously described [18]. For $\mathrm{Na}_{\mathrm{V}}$ channel recordings, the external recording solution contained (in $\mathrm{mM}$ ): $137 \mathrm{NaCl}, 4 \mathrm{KCl}, 1.8 \mathrm{CaCl}_{2}, 1 \mathrm{MgCl}_{2}, 10$ HEPES, 10 glucose, adjusted to $\mathrm{pH} 7.4$ with $\mathrm{NaOH}$, while for $\mathrm{Ca}_{\mathrm{v}} 1.2, \mathrm{Ca}_{\mathrm{v}} 2.1$, and $\mathrm{Ca}_{\mathrm{v}} 2.2$, the external solution contained (in $\mathrm{mM}$ ): $139 \mathrm{CsCl}, 5 \mathrm{BaCl}_{2}, 1 \mathrm{MgCl}_{2}$, 10 HEPES, 10 glucose, adjusted to $\mathrm{pH} 7.4$ with $\mathrm{CsOH}$. For $\mathrm{Ca}_{\mathrm{v}} 3.1$, $\mathrm{Ca}_{\mathrm{v}} 3.2$, and $\mathrm{Ca}_{\mathrm{v}} 3.3$ channel recordings, the external recording solution contained (in mM): $142 \mathrm{CsCl}, 2 \mathrm{CaCl}_{2}, 1 \mathrm{MgCl}_{2}, 10$ HEPES, 10 glucose, adjusted to $\mathrm{pH} 7.4$ with $\mathrm{CsOH}$. For all recordings, the internal patch pipette solution contained (in $\mathrm{mM}$ ): $126.5 \mathrm{CsMeSO}_{4}, 2$ $\mathrm{MgCl}_{2}, 11$ EGTA, 10 HEPES, $2 \mathrm{Na}_{2}$-ATP, adjusted to $\mathrm{pH} 7.3$ with $\mathrm{CsOH}$. For all voltage-clamp protocols liquid junction potentials were left uncorrected. Recordings were digitized at $5 \mathrm{kHz}$ and low-pass filtered at $1 \mathrm{kHz}$.

\subsection{Animals}

All electrophysiological experiments involving animals and their care were performed in accordance with the recommendations of the Canadian Council on Animal Care and were according to the animal care regulations and policies of the University of British Columbia. For in vivo pain testing experiments, male Sprague-Dawley rats (225-300 g; Harlan; Indianapolis, IN) were maintained on a 12/12 h light/dark cycle and provided food and water ad libitum. All pain testing experiments were performed nder protocols approved by the Institutional Animal Care and Use Committee in compliance with policies set forth by the National Institutes of Health of the United States.

\subsection{Voltage-clamp recordings on DRG neurons}

Male Wistar rats (P25 to P30) were anesthetized with isoflurane and decapitated. DRG were removed, cut into pieces, and placed in $\mathrm{Ca}^{2+}$ and $\mathrm{Mg}^{2+}$-free Hank balanced salt solution containing (in $\mathrm{mM}$ ): $138 \mathrm{NaCl}, 5.3 \mathrm{KCl}, 0.4 \mathrm{KH}_{2} \mathrm{PO}_{4}, 0.3 \mathrm{Na}_{2} \mathrm{HPO}_{4}, 6$ D-glucose, $10 \mathrm{HEPES}$, and $2 \mathrm{mg} / \mathrm{mL}$ collagenase (Type I, Worthington, Lakewood, New Jersey), and 200 units of DNasel (Worthington, Lakewood, NJ). Ganglia were incubated for $45 \mathrm{~min}$ at $37^{\circ} \mathrm{C}$ and subsequently placed in L-15 media supplemented with $10 \%$ fetal bovine serum, 100 units of penicillin, $100 \mu \mathrm{g}$ streptomycin, $5 \mathrm{mM}$ HEPES, and $250 \mathrm{ng} / \mathrm{mL}$ nerve growth factor (all from Invitrogen, Carlsbad, CA). Cells were dispersed with fire-polished Pasteur pipettes and plated on glass coverslips coated with $1 \mathrm{mg} / \mathrm{mL}$ poly-L-lysine and $5 \mu \mathrm{g} / \mathrm{mL}$ laminin (Sigma, St. Louis, MO). Coverslips were incubated at $37^{\circ} \mathrm{C}$ for $1-2 \mathrm{~h}$ and transferred to $4{ }^{\circ} \mathrm{C}$ for storage. Within $72 \mathrm{~h}$, neurons were subjected to voltage-clamp analyses with borosilicate glass patch pipettes with resistances of 2.5-5 M $\Omega$. The external recording solution contained (in $\mathrm{mM}$ ): $137 \mathrm{NaCl}, 5 \mathrm{TEACl}, 10$ D-glucose, $1.8 \mathrm{CaCl}_{2}, 1 \mathrm{MgCl}_{2}, 10 \mathrm{HEPES}$, 0.0005 TTX, $0.001 \mathrm{LaCl}_{3}$ adjusted to $\mathrm{pH} 7.4$ with $\mathrm{NaOH}$ and 300 mOsm with sucrose. The internal patch pipette solution contained (in $\mathrm{mM}$ ): $120 \mathrm{CsCl}, 2 \mathrm{MgCl}_{2}, 10$ EGTA, 10 HEPES, 3 MgATP, 6 Tris $_{2}$-phosphocreatine, and 0.4 Tris-GTP adjusted to $\mathrm{pH}$ 7.2 with $\mathrm{CsOH}$ and 290 mOsm. Only neurons with stable leak currents less than $100 \mathrm{pA}$ at $-70 \mathrm{mV}$ were used. Recordings were digitized at $20 \mathrm{kHz}$ and low-pass filtered at $1 \mathrm{kHz}$.

\subsection{Current-clamp recordings on DRG neurons}

Male Sprague-Dawley rats (P1 to P4) were anesthetized with $\mathrm{CO}_{2}$ and decapitated. DRG were removed and placed in Ham F-12 supplemented with $10 \%$ horse serum, 50 units of penicillin, and $50 \mu \mathrm{g}$ streptomycin (all media components from Invitrogen). Ganglia were incubated for $15 \mathrm{~min}$ at $37^{\circ} \mathrm{C}$ in F-12 media supplemented with $0.05 \%$ collagenase (Type XI, Sigma), rinsed, and incubated for $10 \mathrm{~min}$ at $37^{\circ} \mathrm{C}$ in phosphate-buffered saline supplemented with $0.12 \%$ trypsin (Invitrogen). Cells were dispersed with fire-polished Pasteur pipettes and plated on glass coverslips coated with $15 \mu \mathrm{g} / \mathrm{mL}$ poly-L-ornithine (Sigma) in F-12 media supplemented with $40 \mathrm{ng} / \mathrm{mL}$ nerve growth factor (Invitrogen). Within $72 \mathrm{~h}$ of plating, neurons were current-clamped with borosilicate glass patch pipettes with resistances of 2.5-5 M 2 . The external recording solution contained (in $\mathrm{mM}$ ): $137 \mathrm{NaCl}, 5 \mathrm{KCl}, 10$ D-glucose, $2 \mathrm{CaCl}_{2}, 2 \mathrm{MgCl}_{2}, 10$ HEPES adjusted to $\mathrm{pH} 7.4$ with $\mathrm{NaOH}$, and 300 mOsm with sucrose. The internal patch pipette solution contained (in mM): $130 \mathrm{KCl}, 5 \mathrm{MgCl}_{2}, 1$ EGTA, 40 HEPES, $2 \mathrm{MgATP}$, and $0.5 \mathrm{Mg}$-GTP adjusted to $\mathrm{pH} 7.2$ with $\mathrm{KOH}$ and $290 \mathrm{mOsm}$ with sucrose. Only neurons with stable leak currents less than $100 \mathrm{pA}$ at $-70 \mathrm{mV}$ were used. A calculated liquid junction potential of $12.2 \mathrm{mV}$ was corrected in all DRG current-clamp recordings. Recordings were digitized at $5 \mathrm{kHz}$ and low-pass filtered at $1 \mathrm{kHz}$.

\subsection{Recordings on lamina I/II spinal cord neurons}

Male Wistar rats (P6 to P9 for voltage-clamp and P15 to P18 for current-clamp recordings) were anesthetized through 
intraperitoneal injection of Inactin (Sigma). The spinal cord was then rapidly dissected out and placed in an ice-cold protective sucrose solution containing (in $\mathrm{mM}$ ): 50 sucrose, $92 \mathrm{NaCl}, 15$ D-glucose, $26 \mathrm{NaHCO}_{3}, 5 \mathrm{KCl}, 1.25 \mathrm{NaH}_{2} \mathrm{PO}_{4}, 0.5 \mathrm{CaCl}_{2}, 7 \mathrm{MgSO}_{4}$, and 1 kynurenic acid, and bubbled with $5 \% \mathrm{CO}_{2} / 95 \% \mathrm{O}_{2}$. The meninges, dura, and dorsal and ventral roots were then removed from the lumbar region of the spinal cord under a dissecting microscope. The "cleaned" lumbar region of the spinal cord was glued to the vibratome stage and immediately immersed in ice-cold bubbled sucrose solution. For current-clamp recordings, 300- to $350-\mu \mathrm{m}$ parasagittal slices were cut to preserve the dendritic arbor of lamina I neurons, while 350 - to $400-\mu \mathrm{m}$ transverse slices were prepared for voltage-clamp $\mathrm{Na}_{V}$ channel recordings. Slices were allowed to recover for $1 \mathrm{~h}$ at $35^{\circ} \mathrm{C}$ in Ringer solution containing (in mM): $125 \mathrm{NaCl}, 20$ D-glucose, $26 \mathrm{NaHCO}_{3}, 3 \mathrm{KCl}, 1.25 \mathrm{NaH}_{2} \mathrm{PO}_{4}$ $2 \mathrm{CaCl}_{2}, 1 \mathrm{MgCl}_{2}, 1$ kynurenic acid, and 0.1 picrotoxin, bubbled with $5 \% \mathrm{CO}_{2} / 95 \% \mathrm{O}_{2}$. The slice recovery chamber was then returned to room temperature $\left(20-22^{\circ} \mathrm{C}\right)$, and all recordings were performed at this temperature.

Neurons were visualized with IR-DIC optics (Zeiss Axioskop 2 FS plus, Gottingen, Germany), and neurons from lamina I and the outer layer of lamina II were selected on the basis of their location relative to the substantia gelatinosa layer. Neurons were subjected to patch-clamp analyses with borosilicate glass patch pipettes with resistances of 3-6 M $\Omega$. Voltage-clamp recordings of $\mathrm{Na}_{V}$ currents in lamina I/II neurons were performed after slowly (2-5 min) pulling the neurons off the slice to enable adequate space clamp (entire soma isolation [ESI], technique as in Safronov et al. [38]; see Suppl. Fig. 4). For current-clamp recordings of lamina I/II neurons in the intact slice, the external recording solution was the above Ringer solution, while the internal patch pipette solution contained (in $\mathrm{mM}$ ): 140 KGluconate, $4 \mathrm{NaCl}, 10$ HEPES, 1 EGTA, $0.5 \mathrm{MgCl}_{2}, 4$ MgATP, $0.5 \mathrm{Na}_{2} \mathrm{GTP}$, adjusted to $\mathrm{pH} 7.2$ with $5 \mathrm{M} \mathrm{KOH}$ and to 290 mOsm with D-mannitol (if necessary). Only tonic firing neurons were selected for current-clamp experiments, while phasic, delayed-onset, and single-spike neurons were discarded [34]. For voltage-clamp recordings of pharmacologically isolated $\mathrm{Na}_{V}$ currents [38] in ESI lamina I/II neurons, the external recording solution was a modified TEA-Ringer solution containing (in $\mathrm{mM}$ ): 95 $\mathrm{NaCl}, 20 \mathrm{TEACl}, 11$ D-glucose, $25 \mathrm{NaHCO}_{3}, 5.6 \mathrm{KCl}, 1 \mathrm{NaH}_{2} \mathrm{PO}_{4}, 0.1$ $\mathrm{CaCl}_{2}, 5 \mathrm{MgCl}_{2}, 1$ kynurenic acid, 0.1 picrotoxin, while the internal patch pipette solution contained (in $\mathrm{mM}$ ): $140 \mathrm{CsCl}, 5.8 \mathrm{NaCl}, 1$ $\mathrm{MgCl}_{2}$, 3 EGTA, 10 HEPES, 4 MgATP, $0.5 \mathrm{Na}_{2} \mathrm{GTP}$, adjusted to $\mathrm{pH}$ 7.3 with $\mathrm{NaOH}$ and 290 mOsm with D-mannitol (if necessary). Only neurons with stable leak currents less than $100 \mathrm{pA}$ (at $-100 \mathrm{mV}$ ) for voltage-clamp and with resting membrane potentials $\left(V_{\text {rest }}\right)$ more negative than $-50 \mathrm{mV}$ for current-clamp were used for subsequent experiments. A calculated liquid junction potential of $14.6 \mathrm{mV}$ was corrected for current-clamp recordings. Recordings were digitized at $50 \mathrm{KHz}$ and low-pass filtered at 2.4 or $10 \mathrm{kHz}$ for voltage-clamp and current-clamp recordings, respectively.

\subsection{In vivo pain testing}

Spinal nerve ligation (SNL) injury was performed by tight ligation of the L5 and L6 spinal nerves according to the procedure of Kim and Chung [24] in Harlan Sprague-Dawley rats. Rats that exhibited motor deficiency (such as paw dragging or dropping) or showed no tactile or thermal hypersensitivity were excluded from further testing. The experimenter was blinded to the drug pretreatment. Fourteen days after SNL injury, tactile paw withdrawal threshold and thermal paw withdrawal latency were measured. Response thresholds to innocuous mechanical stimuli were evaluated by determining paw withdrawal threshold after probing the paw with a series of calibrated Von Frey filaments [7]. The withdrawal threshold was determined by sequentially increasing and decreasing the stimulus strength (up-and-down method) and analyzed by a Dixon nonparametric test. Data are expressed as the mean withdrawal threshold. Response thresholds to noxious thermal stimuli were determined by measuring the latency of paw withdrawal from a focused beam of radiant heat on the surface of the hind paw using a plantar analgesia meter (Ugo Basile, Italy) by the Hargreaves method [16]. A maximum cutoff of $33 \mathrm{~s}$ was used to prevent tissue damage. For the hot-plate test, naive rats were placed on a $52{ }^{\circ} \mathrm{C}$ metal hot plate to measure the latency of paw flinching or licking before or $1 \mathrm{~h}$ after drug administration. A cutoff of $30 \mathrm{~s}$ was used.

\subsection{Cardiovascular liability studies}

Isolated New Zealand White rabbit $(2.5-3.5 \mathrm{~kg}$ ) hearts were AV ablated, perfused in a retrograde manner, and paced at a stimulation rate of $1 \mathrm{~Hz}$ (basic cycle length $=1 \mathrm{~s}$ ). The stabilization period was at least $15 \mathrm{~min}$ long before obtaining control responses. Experiments were performed at $37 \pm 3{ }^{\circ} \mathrm{C}$. Each heart acted as its own vehicle control before application of Z123212. Concentrations of 3,10 , and $30 \mu \mathrm{M} Z 123212$ were applied sequentially, in ascending order, for exposure periods of at least $15 \mathrm{~min} /$ concentration to allow for equilibration within the heart tissue. The QT interval and QRS duration were calculated by ECG Auto software (EMKA Technologies, Falls Church, VA).

\subsection{Pharmacokinetic studies}

Z123212 was provided as the $\mathrm{HCl}$ salt for pharmacokinetic analysis. All dosing was based on the free base weight of the compound. Harlan male Sprague-Dawley rats were fasted overnight before dose administration of Z123212 in 0.5\% carboxy methyl cellulose. Plasma samples were collected via jugular cannulae from 3 animals per time point at $0.25,0.5,0.75,1,2$, and $4 \mathrm{~h}$. Brains were collected from 3 animals per time point at 1 and $4 \mathrm{~h}$. Plasma and brain samples were stored below $-70{ }^{\circ} \mathrm{C}$ until analysis could be performed by a research-grade liquid chromatography/tandem mass spectrometry assay. Mean Z123212 concentrations in the plasma and brain and noncompartmental pharmacokinetic analysis of the plasma data were performed by WinNonlin software, version 5.0.1 (Pharsight, Mountain View, CA).

\subsection{Compounds and perfusion}

Unless otherwise indicated, all compounds were obtained from Sigma. For in vitro studies, Z123212 was prepared as 30 or $100 \mathrm{mM}$ stock solutions in dimethyl sulfoxide and stored at $-80^{\circ} \mathrm{C}$. Stock aliquots were thawed and used for a maximum of 2 weeks. The highest concentration of dimethyl sulfoxide in the extracellular solutions did not exceed $0.1 \%$, a concentration that did not detectably affect current-clamp or voltage-clamp recording properties. A closed perfusion system $(10 \mathrm{~mL})$ was used for spinal cord slice recordings, with a flow rate of between 2 and $4 \mathrm{~mL} / \mathrm{min}$. For in vivo studies, Z123212 was dissolved in $0.5 \%$ carboxy methyl cellulose at a concentration of $6 \mathrm{mg} / \mathrm{mL}$.

\subsection{Data analysis}

Figures and fittings utilized Microcal Origin 7.5 (Northampton, MA). Current-voltage relationships were fitted with the modified Boltzmann equation: $I=\left[G_{\max } \times\left(V_{\mathrm{m}}-E_{\text {rev }}\right)\right] /\left[1+\exp \left(/ k_{\mathrm{a}}\right)\right]$, where $V_{\mathrm{m}}$ is the test potential, $V_{0.5 \mathrm{a}}$ is the half-activation potential, $E_{\mathrm{rev}}$ is the extrapolated reversal potential, $G_{\max }$ is the maximum slope conductance, and $k_{\mathrm{a}}$ reflects the slope of the activation curve. Data from concentration dependence studies were fitted with the equation $y=\left[\left(A_{1}-A_{2}\right) /\left\{1+\left(x / x_{0}\right)^{P}\right\}+A_{2}\right]$, where $A_{1}$ is initial amplitude 
$(=0)$ and $A_{2}$ is final block value, $x_{0}$ is IC $_{50}$ (concentration causing $50 \%$ inhibition of currents), and $P$ gives a measure of the steepness of the curve. Statistical significance was determined by paired or unpaired Student's $t$ tests and 1-way or repeated measures ANOVA followed by Tukey's multiple comparison test, and significant values were set as indicated in the text and figure legends. All data are given as means \pm standard errors.

\section{Results}

\subsection{Design and synthesis of Z123212}

Given the well-documented roles of $\mathrm{Ca}_{\mathrm{v}} 3.2 \mathrm{~T}$-type channels and $\mathrm{Na}_{V}$ channels in modulating the excitability of DRG neurons, we set out to rationally design a mixed ion channel blocker that may have synergistic effects in attenuating pain signaling. As part of a rationale scaffold-based design and screening program to develop subtype-selective $\mathrm{N}$-type and $\mathrm{T}$-type $\mathrm{Ca}_{\mathrm{V}}$ blockers, the small organic compound Z121912 (molecular weight $=521$; Fig. 1) was initially designed on the basis of previous backbones identified as exhibiting promising $\mathrm{Ca}_{\mathrm{V}}$ blocking and preclinical characteristics [32,47]. In particular, the bis- $\mathrm{CF}_{3}$ aryl amide group of $\mathrm{Z121912}$ was a preferred structural feature from the aspect of T-type $\mathrm{Ca}_{\mathrm{V}}$ blocking potency $\left(\mathrm{IC}_{50}=64 \mathrm{nM}\right)$. However, from a drug discovery perspective Z121912 possessed potential cardiovascular liability in that it also potently blocked the hERG potassium channel (IC $50 \sim 100 \mathrm{nM}$ ). In order to reduce the hERG liability, the benzhydrol group of Z121912 was either removed $($ Z123875; molecular weight $=355)$ or replaced with an oxygenated piperazine (Z123212; molecular weight = 369; Fig. 1; Suppl. Fig. 1). Both derivatives exhibited significantly improved profiles against the hERG potassium channel $\left(\mathrm{IC}_{50} \mathrm{~S}>10 \mu \mathrm{M}\right)$ with Z123212 being selected for further preclinical assessment on the basis of its favorable pharmacokinetic properties.

\subsection{Z123212 stabilizes the slow-inactivated state of $\mathrm{Ca}_{V} 3.2 \mathrm{~T}$-type channels}

The blocking activity of Z123212 was initially tested against recombinant $\mathrm{Ca}_{\mathrm{v}} 3.2$ channels expressed in HEK cells by using standard depolarizing test pulses from a hyperpolarized holding
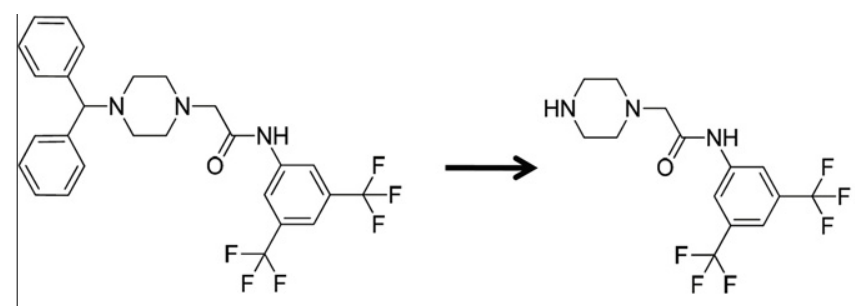

Z121912

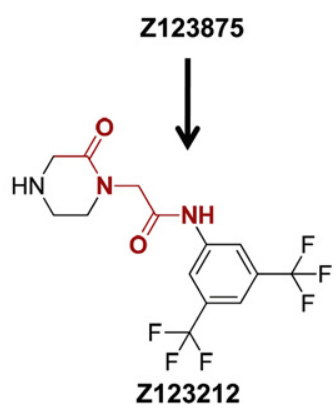

Fig. 1. Structural features of Z123212. Z123875 and Z123212 are derivatives of the high-affinity piperazine T-type antagonist, Z121912. The dipeptide backbone of Z123212 is highlighted in red. potential $\left(V_{\text {hold }} ;-110 \mathrm{mV}\right)$ that would place the channels largely in the closed state. Somewhat surprisingly, even at relatively high concentrations, Z123212 caused minimal inhibition of recombinant $\mathrm{Ca}_{\mathrm{V}} 3.2$ channels when activated from the closed state $\left(\mathrm{IC}_{50}\right.$ $\gg 10 \mu \mathrm{M}$, Fig. 2A and B). We assessed the effects of Z123212 on other $\mathrm{Ca}_{\mathrm{v}} 3.2$ channel properties and found that $10 \mu \mathrm{M} \mathrm{Z} 123212$ also had no significant $(P>.05)$ effect on the voltage dependence of fast channel inactivation (control, $V_{1 / 2 \text { Fastlnact }}=-61 \pm 1 \mathrm{mV}$, $n=5 ; 10 \mu \mathrm{M} ; \mathrm{Z123212}, V_{1 / 2 \text { FastInact }}=-66 \pm 3 \mathrm{mV}, n=4$; data not shown). As previously observed for $\mathrm{Ca}_{\mathrm{v}} 3.1$ channels [17], we next examined whether Cav3.2 channels undergo a slow inactivation process (Fig. 2C). Z123212 $(10 \mu \mathrm{M})$ significantly $(P<.05)$ increased the extent of $\mathrm{Ca}_{\mathrm{v}} 3.2$ channel slow inactivation at specific membrane potentials and also caused a significant $6 \mathrm{mV}$ hyperpolarizing shift in the voltage dependence of $\mathrm{Ca}_{\mathrm{v}} 3.2$ channel slow inactivation (Fig. 2C; $P<.05$ ). The recovery from inactivation
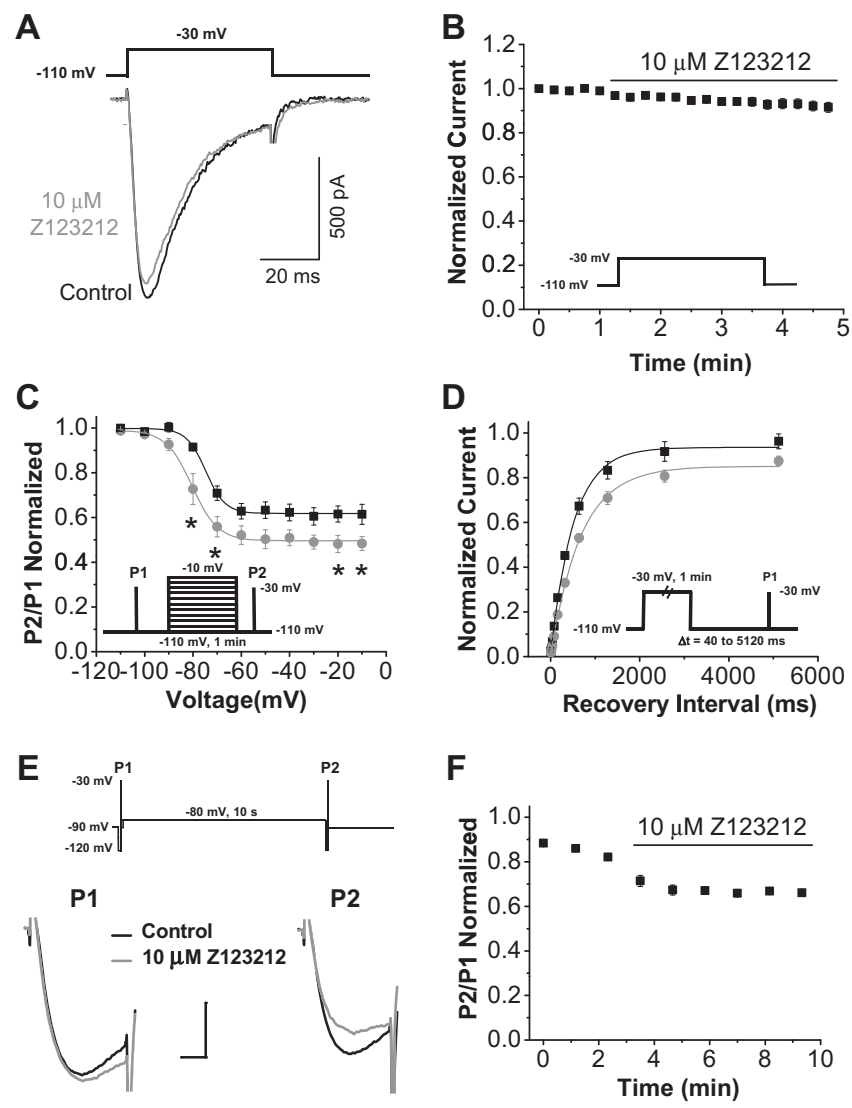

Fig. 2. Z123212 selectively alters the slow-inactivated state of $\mathrm{Ca}_{\mathrm{v}} 3.2$ channels. (A) Representative traces of recombinant $\mathrm{Ca}_{\mathrm{v}} 3.2$ channels during depolarizing steps

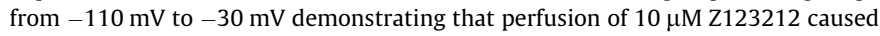
minimal inhibition of $\mathrm{Ca}_{\mathrm{v}} 3.2$ channels when activated from hyperpolarized potentials. Scale bar $x=20 \mathrm{~ms}, y=500 \mathrm{pA}$. (B) Average time course of normalized $\mathrm{Ca}_{\mathrm{V}} 3.2$ channel peak current values before and during perfusion of $10 \mu \mathrm{M} \mathrm{Z123212}$ $(n=11)$. (C) Z123212 $(10 \mu \mathrm{M})$ caused a significant $(P<.05)$ hyperpolarizing shift in the voltage dependence of $\mathrm{Ca}_{\mathrm{V}} 3.2$ channel slow inactivation (control, $V_{1 / 2 \text { Slowlnact }}=$ $-74 \pm 1 \mathrm{mV}, n=4 ; 10 \mu \mathrm{M} \mathrm{Z123212}, V_{1 / 2 \text { Slowinact }}=-80 \pm 2 \mathrm{mV}, n=5$ ). $\mathrm{Z} 123212$ also caused a significant $\left({ }^{*} \mathrm{P}<.05\right)$ enhancement of the extent of $\mathrm{Na}_{\mathrm{V}}$ channel slow inactivation at potentials of $-80,-70,-20$, and $-10 \mathrm{mV}$. (D) Z123212 (10 $\mu \mathrm{M})$ significantly $(P<.005, n=4-5)$ slowed the recovery from Cav3.2 channel slow inactivation. Recordings in both (C) and (D) were unpaired and time-matched between control and Z123212 treatment groups to eliminate potential timedependent changes in parameters. (E) Representative traces demonstrating that Z123212 selectively inhibited slow-inactivated T-type currents (P2 traces) in dissociated dorsal root ganglia (DRG) neurons. Scale bar: $x=5 \mathrm{~ms}, y=1000 \mathrm{pA}$. (F) Average time course of the ratio of P2 peak current P1 peak current demonstrating that Z123212 increases the extent of T-type channel slow inactivation in DRG neurons $(n=4)$. Insets illustrate voltage step waveforms. 
parameter for $\mathrm{Ca}_{\mathrm{V}} 3.2$ channels has been linked to changes in neuronal membrane excitability [33]; thus, we tested the effect of Z123212 on $\mathrm{Ca}_{\mathrm{v}} 3.2$ recovery from slow inactivation. Application of Z123212 significantly $(P<.01)$ slowed the recovery from $\mathrm{Ca}_{\mathrm{V}} 3.2$ channel slow inactivation at concentrations of $3 \mu \mathrm{M}$ and greater (control, $\tau_{\text {recov }}=510 \pm 30 \mathrm{~ms}, \quad n=4 ; 3 \mu \mathrm{M}$; Z123212, $\tau_{\text {recov }}=650 \pm 20 \mathrm{~ms}, n=4 ; 10 \mu \mathrm{M} ; \mathrm{Z} 123212, \tau_{\text {recov }}=680 \pm 20 \mathrm{~ms}$, $n=5$; Fig. 2D). The $\mathrm{Ca}_{\mathrm{v}} 3.2 \mathrm{~T}$-type channel isoform mediates the majority of whole cell T-type current within DRG neurons $[1,6,8,42]$; thus, we also tested the effects of Z123212 on T-type currents within isolated DRG neurons. Consistent with the recombinant $\mathrm{Ca}_{\mathrm{V}} 3.2$ results, $\mathrm{Z123212}(10 \mu \mathrm{M})$ was found to selectively stabilize the slow-inactivated state of T-type currents in isolated DRG neurons (Fig. 2E and F).

\subsection{Z123212 inhibits recombinant $\mathrm{Na}_{V}$ and $\mathrm{Ca}_{V}$ channels by modulating slow inactivation}

Both TTX-sensitive $\mathrm{Na}_{\mathrm{V}} 1.7$ and TTX-resistant $\mathrm{Na}_{\mathrm{V}} 1.8$ channels are highly expressed in DRG neurons and exhibit overlapping distributions and functional roles with $\mathrm{Ca}_{\mathrm{v}} 3.2$ T-type channels $[10,19]$. Hypothesizing that $\mathrm{Z} 123212$ may also alter $\mathrm{Na}_{\mathrm{V}}$ channel activity, we tested whether Z123212 could inhibit slowinactivated recombinant $\mathrm{Na}_{V}$ channels. In order to induce slow inactivation, sweeps were elicited every $30 \mathrm{~s}$ that included a $10-\mathrm{s}$ conditioning pulse to $-20 \mathrm{mV}$, followed by a short hyperpolarizing step to remove fast inactivation and then a depolarizing test pulse (P2; as described in [40]). We found that perfusion of Z123212 caused a robust inhibition of both recombinant $\mathrm{Na}_{\mathrm{V}} 1.7$ and $\mathrm{Na}_{\mathrm{V}} 1.8 \mathrm{P} 2$ currents that was even greater than that observed for $\mathrm{Ca}_{\mathrm{V}} 3.2$ channels (Fig. $3 \mathrm{~A}$ and $\mathrm{B}$ ). Concentration-dependent response studies revealed that $\mathrm{Z} 123212$ inhibited $\mathrm{Na}_{\mathrm{V}} 1.7$ channels with an $\mathrm{IC}_{50}=17 \mu \mathrm{M}$ and $\mathrm{Na}_{\mathrm{V}} 1.8$ channels with an $\mathrm{IC}_{50}=9.2 \mu \mathrm{M}$ (Fig. 3C).
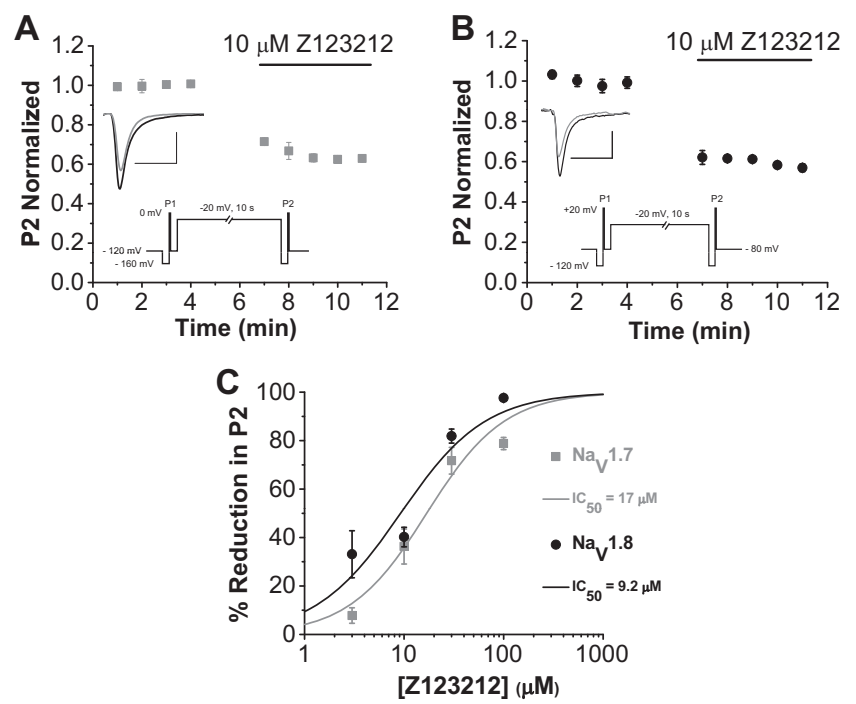

Fig. 3. Z123212 inhibits slow-inactivated $\mathrm{Na}_{v} 1.7$ and $\mathrm{Na}_{\mathrm{v}} 1.8$ channels. The effects of Z123212 on slow-inactivated recombinant $\mathrm{Na}_{\mathrm{v}} 1.7$ (A) and $\mathrm{Na}_{\mathrm{v}} 1.8$ (B) channels were assessed using a test pulse (P2) that followed a 10-s conditioning prepulse to $-20 \mathrm{mV}$. (A) Plot of time course of normalized P2 current amplitude showing that application of $10 \mu \mathrm{M}$ Z123212 reduced the amplitude of recombinant $\mathrm{Na}_{\mathrm{V}} 1.7$ currents by $36 \pm 7 \%(n=4)$. (Top inset) Representative P2 traces with (gray) and without (black) $10 \mu \mathrm{M}$ Z123212. Scale bar: $x=5 \mathrm{~ms}, y=1000 \mathrm{pA}$. (B) Plot of time course of normalized P2 current amplitude showing that application of $10 \mu \mathrm{M}$ Z123212 reduced the amplitude of recombinant $\mathrm{Na}_{\mathrm{V}} 1.8$ currents by $40 \pm 4 \%(n=4)$. (Top inset) Representative P2 traces with (gray) and without (black) $10 \mu \mathrm{M}$ Z123212. Scale bar: $x=5 \mathrm{~ms}, y=250 \mathrm{pA}$. (C) Concentration-dependent response curves for Z123212 inhibition of P2 currents for recombinant $\mathrm{Na}_{\mathrm{V}} 1.7$ channels $\left(\mathrm{IC}_{50}=17 \mu \mathrm{M}\right)$ and $\mathrm{Na}_{\mathrm{V}} 1.8$ channels $\left(\mathrm{IC}_{50}=9.2 \mu \mathrm{M}\right) . n=3-5$ for all concentrations.
Because Z123212 stabilized the slow-inactivated state of $\mathrm{Ca}_{\mathrm{V}} 3.2$ T-type and $\mathrm{Na}_{\mathrm{v}} 1.7 / \mathrm{Na}_{\mathrm{v}} 1.8$ channels, it was of interest to test whether it also acted on other $\mathrm{Na}_{V}$ and $\mathrm{Ca}_{\mathrm{V}}$ channel classes. Similar to that for $\mathrm{Ca}_{\mathrm{v}} 3.2 \mathrm{~T}$-type and $\mathrm{Na}_{\mathrm{v}} 1.7 / \mathrm{Na}_{\mathrm{v}} 1.8$ channels, application of $10 \mu \mathrm{M}$ Z123212 did not cause significant tonic block of other $\mathrm{Ca}_{\mathrm{V}}$ and $\mathrm{Na}_{\mathrm{V}}$ isoforms tested (Suppl. Fig. 2). In contrast, $10 \mu \mathrm{M}$ Z123212 was shown to selectively stabilize the putative slowinactivated states of exogenously expressed $\mathrm{Ca}_{\mathrm{V}} 1.2$ (L-type), $\mathrm{Ca}_{\mathrm{V}} 3.1$ (T-type), $\mathrm{Ca}_{\mathrm{v}} 3.3$ (T-type), and $\mathrm{Na}_{\mathrm{V}} 1.5$ channels, with an inhibition of P2 currents (after 10-s depolarizing conditioning pulses) ranging from $\sim 30 \%$ to $60 \%$. However, Z123212 did not uniformly alter slow inactivation states as the compound had no effect ( $<15 \%$ P2 inhibition) on the $\mathrm{Ca}_{\mathrm{v}} 2.1$ (P/Q-type) and $\mathrm{Ca}_{\mathrm{v}} 2.2$ (N-type) isoforms (Suppl. Fig. 2). Taken together, Z123212 selectively stabilizes the slowinactivated states of a subset of ion channel types and does not seem to act as a tonic channel blocker. The selective action of Z123212 on channel slow inactivation may be of particular relevance to the putative hyperexcitable processes associated with various pain states compared to ion channel functioning during normal physiological processes. For example, cardiac $\mathrm{Na}_{\mathrm{V}} 1.5$ channels are adapted to have reduced slow inactivation during the repetitive $(>1 \mathrm{~Hz})$ and prolonged $(\sim 200 \mathrm{~ms})$ depolarizations that occur during AP firing of cardiac myocytes [36]. In support, although Z123212 is able to stabilize the slow-inactivated state of $\mathrm{Na}_{\mathrm{V}} 1.5$ channels under certain experimental conditions (involving step depolarization to $-20 \mathrm{mV}$ for $10 \mathrm{~s}$; Suppl. Fig. 3A), its effects on $\mathrm{Na}_{V} 1.5$ channels activated by simulated cardiac AP waveforms is greatly reduced (Suppl. Fig. 3B).

3.4. Z123212 selectively stabilizes the slow-inactivated state of TTXsensitive $\mathrm{Na}_{V}$ channels in lamina I/II spinal cord neurons

We next set out to determine whether Z123212 could alter native $\mathrm{Na}_{V}$ channels implicated in the nociceptive signaling pathway selectively through its effect on slow inactivation. Voltage-clamp recordings on lamina I/II neurons from spinal cord slices were performed to examine the effects of Z123212 on TTX-sensitive $\mathrm{Na}_{\mathrm{V}}$ currents in nociceptive spinal cord neurons. In order to ensure adequate voltage-clamp of $\mathrm{Na}_{V}$ currents, the ESI technique pioneered by Safronov et al. [38] was used to remove healthy lamina I/II neurons from the slice surface (see Section 2.6 and Suppl. Fig. 4). In this recording configuration, $\mathrm{Na}_{\mathrm{V}}$ currents in lamina I/II neurons were completely blocked by TTX (data not shown; see [38]). Similar to that for recombinant $\mathrm{Na}_{\mathrm{V}}$ and $\mathrm{Ca}_{\mathrm{V}}$ channels, application of $10 \mu \mathrm{M}$ Z123212 did not result in tonic block of native TTX-sensitive $\mathrm{Na}_{V}$ currents during depolarizations from a hyperpolarized state $\left(V_{\text {hold }}=-100 \mathrm{mV}\right.$; Fig. $4 \mathrm{~A}$ and $\mathrm{B}$ ). The perfusion of $10 \mu \mathrm{M}$ Z123212 did result in a small $(-2.4 \pm 0.5 \mathrm{mV}, n=5)$ but significant $(P<.01)$ hyperpolarizing shift in the voltage dependence of $\mathrm{Na}_{\mathrm{V}}$ channel activation (Fig. 4A); however, time-dependent negative shifts in the voltage dependence of activation were also observed during control recordings (data not shown). Thus, this small hyperpolarizing shift was likely not mediated by Z123212.

Application of $10 \mu \mathrm{M}$ Z123212 also had no effect on the voltage dependence of $\mathrm{Na}_{\mathrm{V}}$ channel fast inactivation (100-ms conditioning pulses, Fig. 4C). The voltage dependence of $\mathrm{Na}_{V}$ channel slow inactivation could not be directly assayed by using the native recording system because the neurons would not tolerate the highly hyperpolarized holding potential $\left(V_{\text {hold }}=-120 \mathrm{mV}\right.$ ) required to allow recovery from slow inactivation between pulses. However, during slow inactivation-inducing sweeps, perfusion of $10 \mu \mathrm{M}$ Z123212 caused a robust reduction in the amplitude of lamina I/II neuron $\mathrm{Na}_{V}$ currents during P2 pulses by $45 \pm 7 \%$ ( $n=5$; $P<.02$; Fig. 4D). Analysis of $\mathrm{Na}_{\mathrm{V}}$ current amplitudes in P1 control pulses versus P2 test pulses further demonstrated that Z123212 selectively stabilized the slow-inactivated state of native TTX-sensitive $\mathrm{Na}_{V}$ 

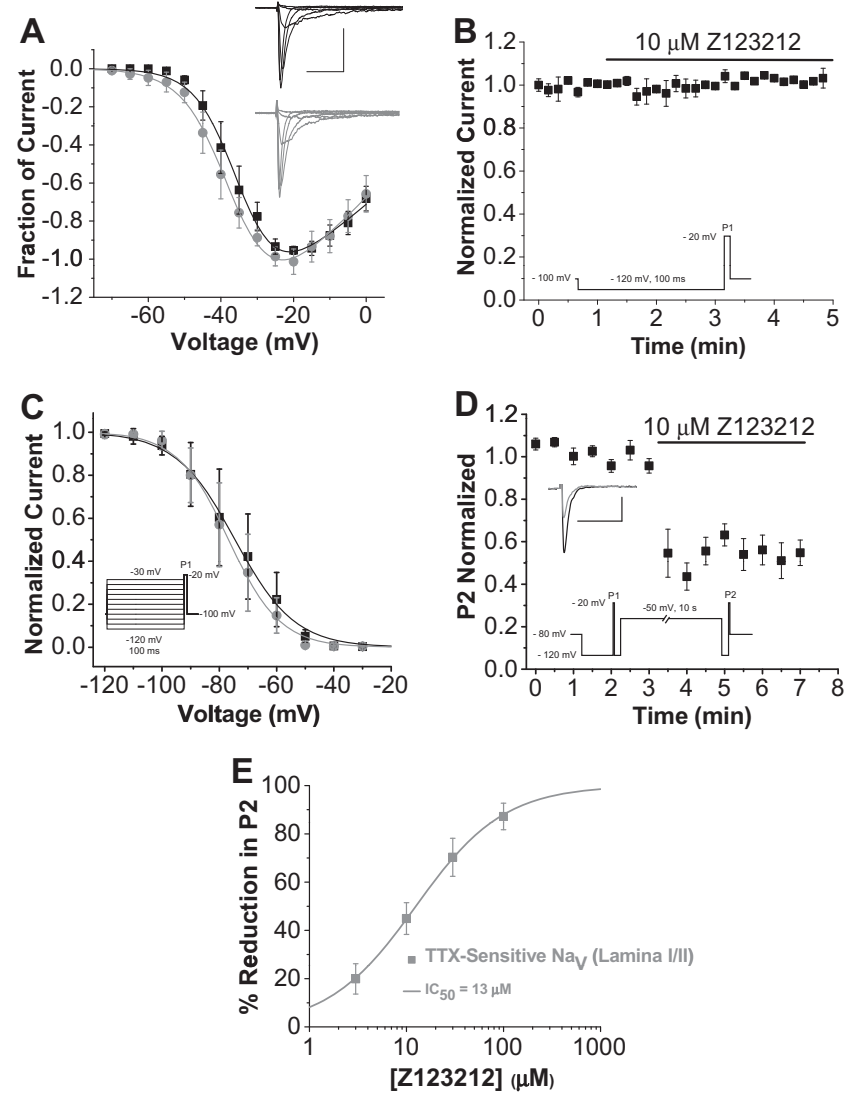

Fig. 4. Z123212 selectively alters the slow inactivation of TTX-sensitive $\mathrm{Na}_{\mathrm{V}}$ channels in lamina I/II neurons. (A) Voltage-clamp recordings of TTX-sensitive $\mathrm{Na}_{V}$ currents in lamina I/II spinal cord neurons. Current values were normalized to the peak current of the control IV relationship, demonstrating no tonic block by $\mathrm{Z} 123212$ at $V_{\text {hold }}=-100 \mathrm{mV}$. (Inset) Representative current traces during depolarization steps from $-60 \mathrm{mV}$ to $-10 \mathrm{mV}$ in $10 \mathrm{mV}$ increments. Scale bar: $x=5 \mathrm{~ms}$, $y=500 \mathrm{pA}$. (B) Average tonic block time course of normalized $\mathrm{Na}_{\mathrm{V}}$ peak current values before and during perfusion of $10 \mu \mathrm{M}$ Z123212. (C) Z123212 $(10 \mu \mathrm{M})$ caused no significant $(P>.05, n=4)$ shift in the voltage dependence of $\mathrm{Na}_{\mathrm{V}}$ channel fast inactivation. (D) Plot of time course of normalized P2 current showing that

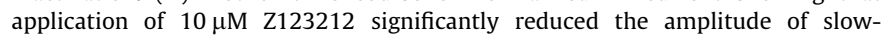
inactivated $\mathrm{Na}_{\mathrm{V}}$ currents. (Top inset) Representative P2 traces with (gray) and without (black) $10 \mu \mathrm{M}$ Z123212. Scale bar: $x=5 \mathrm{~ms}, y=100 \mathrm{pA}$. (E) Concentrationresponse curve for Z123212 inhibition of P2 currents for TTX-sensitive lamina I/II $\mathrm{Na}_{\mathrm{V}}$ channels $\left(\mathrm{IC}_{50}=13 \mu \mathrm{M}\right) \cdot n=3-5$ for all concentrations.

channels (Suppl. Fig. 5). The inhibition by Z123212 of $\mathrm{Na}_{V}$ channels reaching the slow-inactivated state $(\mathrm{P} 2)$ was significant $(P<.05)$ at concentrations of $3 \mu \mathrm{M}$ and higher, with an $\mathrm{IC}_{50}=13 \mu \mathrm{M}$ (Fig. $4 \mathrm{E}$ ).

3.5. Z123212 selectively stabilizes the slow-inactivated state of TTXresistant $\mathrm{Na}_{V}$ channels in peripheral nociceptors

The majority of TTX-resistant $\mathrm{Na}_{\mathrm{V}}$ current in nociceptive DRG neurons is composed of the $\mathrm{Na}_{\mathrm{V}} 1.8$ channel isoform [10]. We next evaluated the effects of Z123212 on pharmacologically isolated TTX-resistant currents in dissociated small diameter DRG neurons. Similar to that for TTX-sensitive $\mathrm{Na}_{\mathrm{V}}$ currents, perfusion of $10 \mu \mathrm{M}$ Z123212 did not result in tonic block of native TTX-resistant $\mathrm{Na}_{V}$ currents when depolarized from a relatively hyperpolarized potential $\left(V_{\text {hold }}=-70 \mathrm{mV}\right.$; Fig. $5 \mathrm{~A}$ and $\mathrm{B}$ ) and also had no significant $(P>.05)$ effect on the voltage dependence of $\mathrm{Na}_{V}$ channel activation (Fig. 5A). Further, while application of $10 \mu \mathrm{M}$ Z123212 did not affect the voltage dependence of fast channel inactivation (Fig. 5C), it significantly $(P<.05)$ enhanced the fraction of $\mathrm{Na}_{\mathrm{V}}$ channels that reached the slow-inactivated state during conditioning prepulses of $-20 \mathrm{mV}$ (as well as more depolarized potentials; Fig. 5D). The
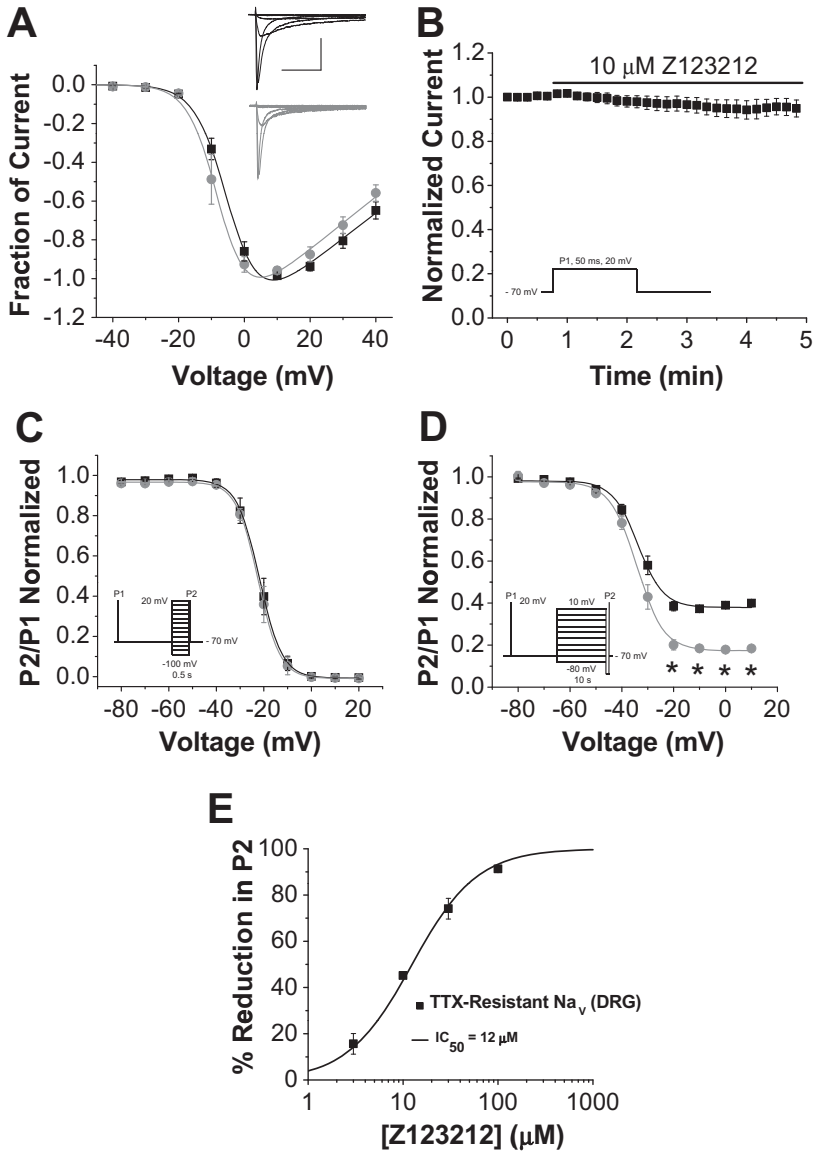

Fig. 5. Z123212 selectively alters the slow inactivation of TTX-resistant $\mathrm{Na}_{\mathrm{V}}$ channels in nociceptive dorsal root ganglia (DRG) neurons. Voltage-clamp recordings of TTX-resistant $\mathrm{Na}_{V}$ currents in small-diameter rat DRG neurons. (A) Treatment with $10 \mu \mathrm{M}$ Z123212 had no effect on the voltage dependence of $\mathrm{Na}_{\mathrm{V}}$ channel activation. (Inset) Representative current traces during depolarizing steps from -40 to $+10 \mathrm{mV}$ in $10-\mathrm{mV}$ increments. Scale bar: $x=50 \mathrm{~ms}, y=2000 \mathrm{pA}$. (B) Average time course of normalized $\mathrm{Na}_{\mathrm{V}}$ channel peak current values before and during perfusion of $10 \mu \mathrm{M} \mathrm{Z123212} \mathrm{(} n=5)$. (C) Application of $10 \mu \mathrm{M} Z 123212 \mathrm{had}$ no significant $(P>.05, n=4)$ effect on the voltage dependence of fast inactivation. (D) Z123212 $(10 \mu \mathrm{M})$ caused a significant $(P<.05, n=5)$ enhancement of the extent of $\mathrm{Na}_{\mathrm{V}}$ channel slow inactivation at conditioning prepulses of $-20 \mathrm{mV}$ and more depolarized potentials. (E) Concentration-response curve for Z123212 inhibition of P2 currents for TTX-resistant DRG $\mathrm{Na}_{\mathrm{V}}$ channels $\left(\mathrm{IC}_{50}=12 \mu \mathrm{M}\right) . n=3-5$ for all concentrations.

concentration dependence for the reduction in P2 current amplitude by Z123212 is shown in Fig. 5E. Using 10-s conditioning prepulses to $-20 \mathrm{mV}$, we calculated an $\mathrm{IC}_{50}=12 \mu \mathrm{M}$.

\subsection{Z123212 reduces the excitability of peripheral nociceptors and} second order spinal cord neurons

Because Z123212 can modulate the activity of several $\mathrm{Na}_{V}$ and $\mathrm{Ca}_{\mathrm{V}}$ channel isoforms linked to neuronal excitability, we used current-clamp recordings to test for possible direct effects of Z123212 on the overall excitability of both DRG and spinal cord lamina I/II neurons. Current-clamp recordings were initially performed on dissociated small diameter $(25 \pm 3 \mathrm{pF}, n=6)$ DRG neurons from neonatal rats. A $350-\mathrm{ms}$ depolarizing current injection step $(-220 \pm 120 \mathrm{pA}, n=6)$ was used to elicit 4-6 APs (Fig. 6A), and this sweep was repeated every $30 \mathrm{~s}$ to ensure that a stable baseline number of APs was reached before applying compound (Fig. 6B). Subsequent perfusion of $10 \mu \mathrm{M}$ Z123212 was found to significantly $(P<.01)$ reduce the number of APs elicited during the depolarizing pulse by $60 \pm 9 \%$ ( $n=6$; Fig. $6 C)$. 

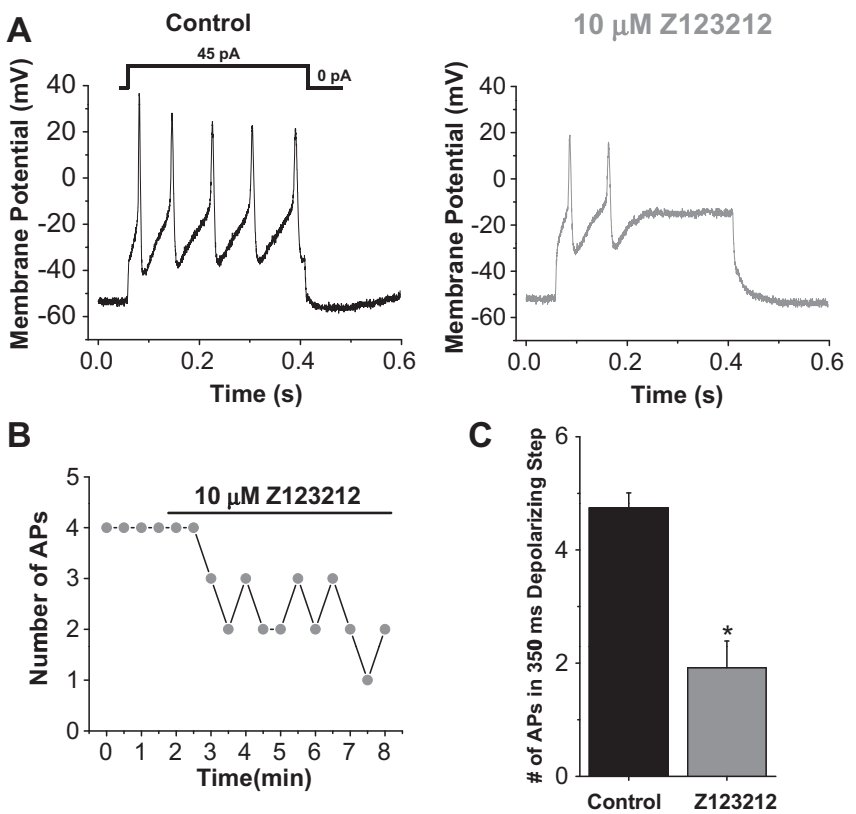

Fig. 6. Z123212 reduces the excitability of small, nociceptive dorsal root ganglia (DRG) neurons. Current-clamp recordings were performed on small $(25 \pm 3 \mathrm{pF}$, $n=6$ ) DRG neurons from P1 to P4 Sprague-Dawley rats. Of 3 DRG neurons tested, 2 were found to be capsaicin sensitive. Firing of 4-6 action potentials (APs) was elicited by 350-ms depolarizing current injections (ranging from 20 to $400 \mathrm{pA}$, depending on cell). (A) Representative traces demonstrating that perfusion of

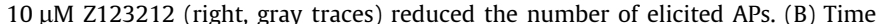
course from another representative neuron demonstrating how perfusion of Z123212 reduced the number of APs during 350-ms depolarizing steps elicited every $30 \mathrm{~s}$. (C) Bar graph showing that $10 \mu \mathrm{M}$ Z123212 caused a significant $(P<.002, n=6)$ reduction in DRG AP firing.

Current-clamp recordings were also performed on intact tonic firing lamina I/II neurons in parasagittal lumbar spinal cord slices from juvenile rats [34]. A current-voltage relationship was repeated every 2 min with $1200 \mathrm{~ms}$ hyperpolarizing/depolarizing current injection steps ranging from $-50 \mathrm{pA}$ to $+80 \mathrm{pA}$ in $+10 \mathrm{pA}$ increments. From this IV relationship, the effect of Z123212 on the number of elicited APs was analyzed for a moderate depolarizing current injection step ( $40 \pm 6 \mathrm{pA}, n=7$ ) that caused only a minor decay in AP amplitude ( $15 \pm 2 \%, n=5)$ over the entire train but still elicited a robust number of APs $(16 \pm 2, n=7)$. Control recordings demonstrated no time-dependent changes in the number of APs during the moderate depolarizing steps, whereas the number of APs decreased with time for depolarizing current injection steps of greater magnitude (data not shown). Application of $10 \mu \mathrm{M}$ Z123212 resulted in a $47 \pm 12 \%(n=7)$ decrease in AP firing during the moderate depolarizing steps (Fig. 7A), while membrane properties including input resistance $\left(R_{\mathrm{N}}\right)$ and $V_{\text {rest }}$ remained unchanged (control, $R_{\mathrm{N}}=490 \pm 60 \mathrm{M} \Omega, n=5, \quad V_{\text {rest }}=-63 \pm 2 \mathrm{mV}$, $n=7 ; 10 \mu \mathrm{M} ; \mathrm{Z} 123212, R_{\mathrm{N}}=460 \pm 50 \mathrm{M} \Omega, n=5, V_{\text {rest }}=-63 \pm 2 \mathrm{mV}$, $n=7$ ). The inhibition of AP firing by Z123212 was concentration dependent with an $\mathrm{IC}_{50}=480 \mathrm{nM}$ (Fig. 7C).

Lacosamide is an anticonvulsant that shares some structural features with Z123212 and has been reported to specifically stabilize the slow inactivation of $\mathrm{Na}_{\mathrm{V}}$ channels $[4,12,40]$. When tested in the spinal cord slice preparation, lacosamide inhibited lamina I/II neuron AP firing approximately 300 times less potently $\left(\mathrm{IC}_{50}=150 \mu \mathrm{M}\right)$ than Z123212 (Fig. 7C). Lacosamide did reach a higher level of AP reduction than Z123212, but only at concentrations $(>100 \mu \mathrm{M})$ well above therapeutic plasma levels for this agent (see Fig. 7C and [4]).

Z123212 reduced AP firing in lamina I/II neurons under conditions where $V_{\text {rest }}$ remained unaltered by tonic current injection
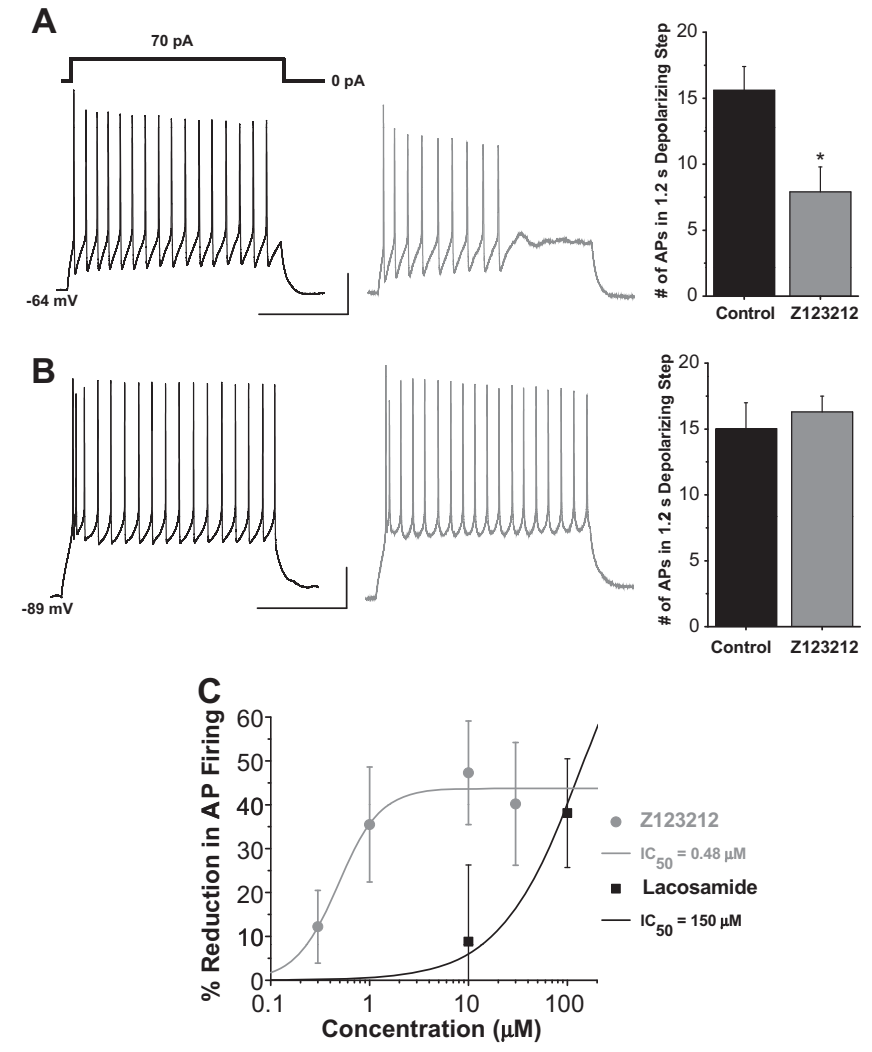

Fig. 7. Z123212 reduces the excitability of spinal cord lamina I/II neurons in a statedependent manner. (A) Current-clamp recordings were performed on dorsal horn lamina I/II neurons from P15 to P18 Wistar rats. Tonic firing of these neurons was induced by $1.2-\mathrm{s}$ depolarizing current injections (ranging from 20 to $70 \mathrm{pA}$, depending on cell). (Left) Representative traces demonstrating that perfusion of $10 \mu \mathrm{M}$ Z123212 (gray traces) reduced the number of elicited action potentials (APs).

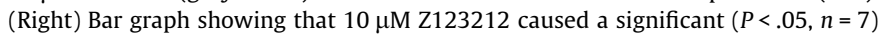
reduction in lamina $\mathrm{I} / \mathrm{II}$ neuron AP firing. $V_{\text {rest }}=-63 \pm 2 \mathrm{mV}, n=7$ for control group. (B) Same experimental conditions as above, except a constant hyperpolarizing current was injected $(-47 \pm 4 \mathrm{pA}, n=3)$ to elicit a more hyperpolarized resting membrane potential $\left(V_{\text {rest }}=-86 \pm 3, n=3\right)$. Perfusion of $10 \mu \mathrm{M} Z 123212$ had no significant $(P>.05)$ effect on lamina I/II neuron AP firing in this more hyperpolarized state. (C) Concentration-response curve for Z123212 and lacosamide on lamina I/II neuron AP firing under conditions as in (A). Z123212 inhibited AP firing with an $\mathrm{IC}_{50}$ value of $0.48 \mu \mathrm{M}$ and a maximal inhibition of $44 \%$, while lacosamide inhibited AP firing with an $\mathrm{IC}_{50}$ value of $150 \mu \mathrm{M}$ and a maximal inhibition approaching $100 \%$ (at concentrations greater than $300 \mu \mathrm{M})(n=3-7$ for all concentrations).

and the depolarizing current injection steps under analysis followed depolarizing current injection steps using an IV protocol. Thus, Z123212 may exert its inhibitory effects on AP firing by stabilizing accumulated slow inactivation of native $\mathrm{Na}_{V}$ and $\mathrm{Ca}_{V}$ channels. In support, repeating the above experiments during tonic hyperpolarizing current injection to elicit a more hyperpolarized $V_{\text {rest }}(-86 \pm 3 \mathrm{mV}, n=3)$ completely eliminated the inhibitory effect of Z123212 (Fig. 7B).

\subsection{Z123212 effectively reverses multiple pain modalities}

We next tested whether the highly state-dependent mechanism of action of Z123212 on nociceptor/spinal cord neuron inhibition translated to an ability to reverse behavioral hypersensitivity in animal models of pain. Oral administration of Z123212 (30 mg/ $\mathrm{kg}$ ) was shown to attenuate both acute thermal hypersensitivity by using the hot-plate test and to a greater extent, chronic mechanical and thermal hypersensitivity assessed using the SNLinduced model of neuropathic pain (Fig. 8). More specifically, Z123212 significantly $(P<.05)$ reversed both tactile allodynia 

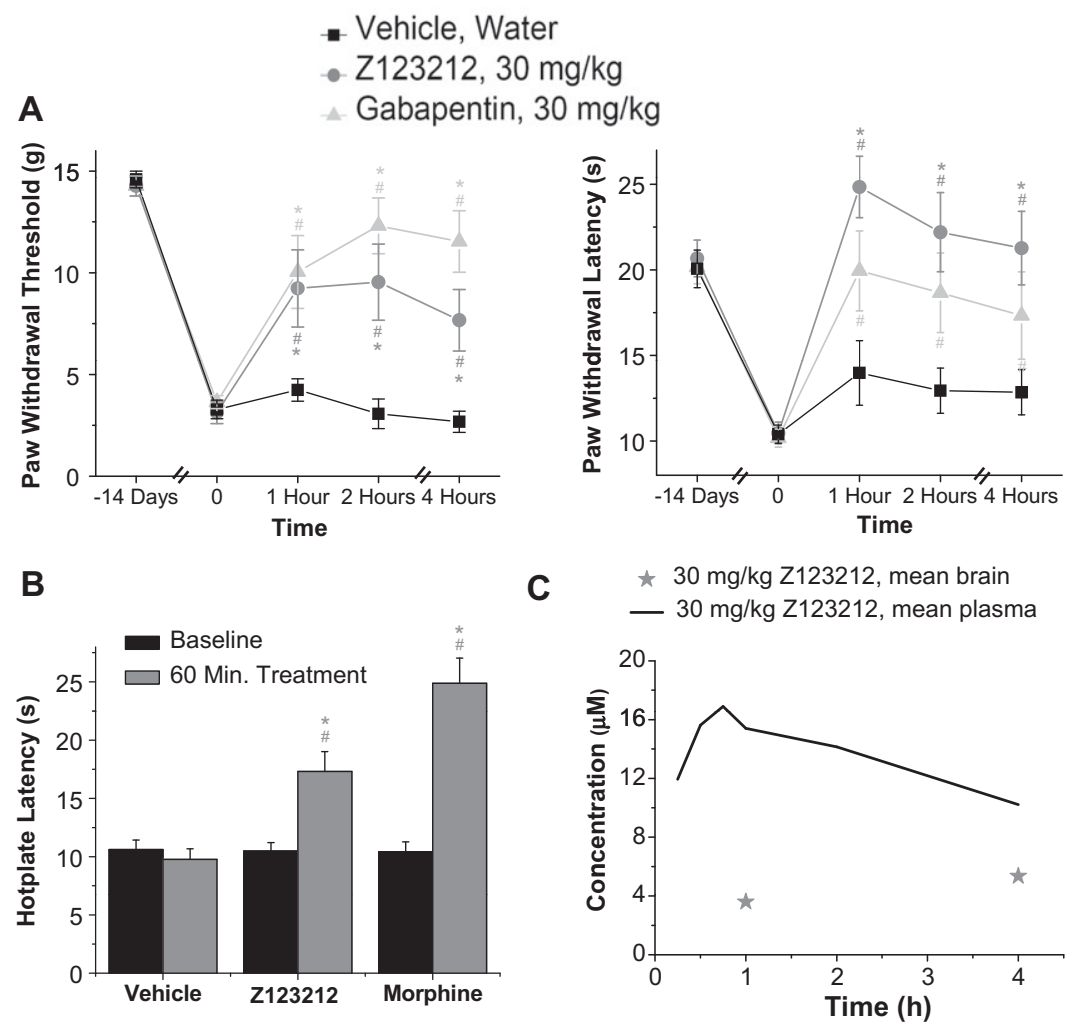

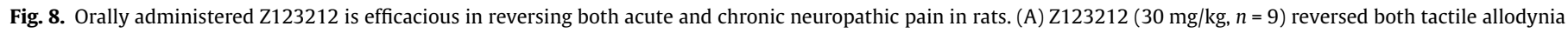

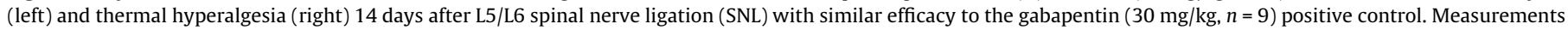

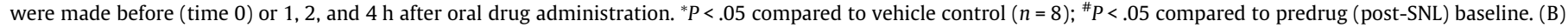

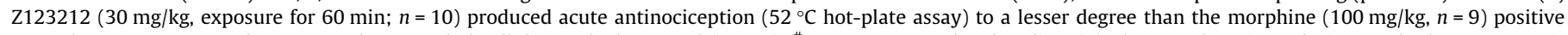

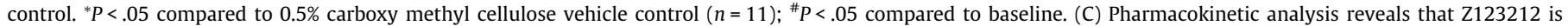
present at concentrations of approximately $3-5 \mu \mathrm{M}$ in rat brain tissue $(n=3)$ and $10-17 \mu \mathrm{M}$ in the plasma $(n=3)$ for the $4 \mathrm{~h}$ after oral administration.

(measured by Von Frey filaments) and thermal hyperalgesia (measured by the Hargreaves method) in SNL rats with an efficacy similar to equivalent doses of gabapentin (Fig. 8A). Z123212 did not cause observable motor deficits at the oral doses used for pain testing (30 mg/kg, oral administration). More comprehensive Rotarod experiments revealed that at doses of $30 \mathrm{mg} / \mathrm{kg}(n=8)$ and $100 \mathrm{mg} / \mathrm{kg}(n=20), \mathrm{Z} 123212$ delivered through the more direct intraperitoneal route caused no detectable motor impairment from 0.25 to $4 \mathrm{~h}$ after administration (data not shown). As Z123212 was shown to stabilize $\mathrm{Na}_{\mathrm{V}} 1.5$ and $\mathrm{Ca}_{\mathrm{V}} 1.2$ L-type channel slow inactivation under certain experimental conditions, we also tested whether Z123212 could affect cardiovascular properties directly. Z123212 tested at 3,10 , and $30 \mu \mathrm{M}$ doses on isolated rabbit hearts did not cause significant $(n=3 ; P>.05)$ alterations in either the QT interval or QRS duration of electrocardiograms. For example, perfusion of Z123212 at doses relevant to the present study $(10 \mu \mathrm{M})$ caused a $-4.7 \pm 2.4 \%$ change $(n=3 ; P>.05)$ in the QT interval and a $-2.3 \pm 2.4 \%(n=3 ; P>.05)$ change in the QRS duration of isolated rabbit hearts.

Pharmacokinetic analysis revealed that Z123212 was well adsorbed at the oral dose used for testing animal efficacy (30 mg/ $\mathrm{kg}$ ) with mean plasma levels ranging between approximately 10 and $17 \mu \mathrm{M}$ for up to $4 \mathrm{~h}$ after oral administration (Fig. 8C). Mean levels of Z123212 in the brain ranged between approximately 3 and $5 \mu \mathrm{M}$ over the same time period (Fig. 8C). Overall, in both the blood and brain, the concentrations of $\mathrm{Z123212}$ reached would be predicted to effectively stabilize $\mathrm{Na}_{V}$ and $\mathrm{Ca}_{V}$ channel slow inactivation and to reduce the excitability of nociceptive DRG and lamina I/II neurons (Figs. 2-7).

\section{Discussion}

We report the design, synthesis and functional characterization of a novel small organic agent (Z123212) that uniquely stabilizes the slow-inactivated state of a subset of $\mathrm{Na}_{V}$ and $\mathrm{Ca}_{V}$ channels. The data suggest that by enhancing the slow inactivation of a combination of TTX-sensitive and TTX-resistant $\mathrm{Na}_{\mathrm{V}}$ and T-type $\mathrm{Ca}_{V}$ currents, Z123212 reduces AP firing in peripheral DRG and lamina I/II spinal cord neurons. We predict that this highly state-specific mechanism underlies the ability of orally administered Z123212 to significantly attenuate thermal and mechanical hypersensitivity in rodent models of both chronic neuropathic pain and acute pain.

\subsection{Mechanism underlying pain-attenuating effects of Z123212}

Z123212 inhibits certain $\mathrm{Na}_{\mathrm{V}}$ and $\mathrm{Ca}_{\mathrm{V}}$ channels by selectively stabilizing the slow-inactivated state over the fast inactivated state. As channel slow inactivation is significantly enhanced during prolonged depolarizations (eg, $-50 \mathrm{mV}$ for $10 \mathrm{~s}$; Fig. 4), Z123212 is predicted to cause pronounced inhibition of $\mathrm{Na}_{V}$ and $\mathrm{Ca}_{\mathrm{V}}$ channels in neurons that are either tonically depolarized or firing in bursts that create sustained depolarizations. In this regard, we observed a Z123212-mediated reduction in AP firing in lamina I/II neurons during prolonged depolarizations from rest (in slices where both excitatory and inhibitory synaptic inputs are blocked) but not when the neurons were tonically hyperpolarized (Fig. 7). During chronic neuropathic pain states, dorsal horn spinal cord neurons can become tonically depolarized and/or exhibit prolonged periods 
of fast depolarized firing due to changes in inhibitory and excitatory inputs $[41,48]$, the remodeling of ion channel expression [26], and alteration of electrical gradients [22]. Z123212 exhibited somewhat greater antinociceptive effects in models of neuropathic pain compared to acute pain (Fig. 8), and we predict that this may be due to the ability of Z123212 to preferentially attenuate hyperexcited neurons within the peripheral and central pain pathways. Future in vivo experiments could verify this by examining the effects of Z123212 on peripheral and spinal cord neurons from animals with enhanced sensitivity for pain [3].

\subsection{Molecular targets of Z123212 action}

Relevant to nociceptive signaling, Z123212 was found to stabilize the slow inactivation of recombinant TTX-sensitive $\mathrm{Na}_{V} 1.7$ channels as well as recombinant TTX-resistant $\mathrm{Na}_{\vee} 1.8$ channels. Both $\mathrm{Na}_{\mathrm{V}}$ isoforms are highly expressed and involved in modulating excitability within peripheral nociceptors [10], and we directly demonstrated that Z123212 inhibits endogenous TTX-resistant $\mathrm{Na}_{V}$ current within DRG neurons. Slow inactivation is induced at potentials near neuronal resting membrane potentials (Figs. 3 and 5; [40]) for both $\mathrm{Na}_{V} 1.7$ and $\mathrm{Na}_{V} 1.8$ isoforms. In this regard, Z123212 likely reduces DRG excitability by acting on multiple $\mathrm{Na}_{\mathrm{V}}$ channel isoforms, which may also include other prominently expressed DRG $\mathrm{Na}_{V}$ isoforms such as $\mathrm{Na}_{\mathrm{V}} 1.1, \mathrm{Na}_{\mathrm{V}} 1.6$, and $\mathrm{Na}_{\mathrm{V}} 1.9$ [10].

To determine how Z123212 influences neurons downstream of nociceptors in the pain pathway, we evaluated the effects of Z123212 on uncontaminated TTX-sensitive $\mathrm{Na}_{\mathrm{V}}$ currents from spinal cord lamina I/II neurons using the ESI recording technique [38]. Z123212 inhibited lamina I/II $\mathrm{Na}_{V}$ currents via their slowinactivated state with a similar potency compared to both recombinant $\mathrm{Na}_{\mathrm{V}} 1.7 / \mathrm{Na}_{\mathrm{V}} 1.8$ currents and DRG TTX-resistant $\mathrm{Na}_{\mathrm{V}}$ currents $\left(\mathrm{IC}_{50}\right.$ values between 9 and $17 \mu \mathrm{M}$ ). Lamina I/II neurons have been shown to contain several functional components of TTX-sensitive $\mathrm{Na}_{v}$ currents [38], although the exact $\mathrm{Na}_{V}$ channel isoforms involved have not been thoroughly explored. As Z123212 stabilizes the slow-inactivated state of functionally distinct $\mathrm{Na}_{\mathrm{V}}$ isoforms, the observed reduction of lamina I/II neuronal excitability may be mediated by one or multiple $\mathrm{Na}_{\mathrm{V}}$ isoforms. It is known that the expression of $\mathrm{Na}_{\mathrm{V}} 1.3$ channel protein is upregulated within dorsal horn neurons in both peripheral and central neuropathic pain models $[14,15]$ and that this isoform (along with $\mathrm{Na}_{V} 1.2$ ) is localized within lamina I/II of the spinal cord [13] (our unpublished observations). In this regard, Z123212 may in part reduce neuropathic pain signaling by enhancing the natural brakes (slow inactivation) of aberrantly expressed $\mathrm{Na}_{\mathrm{V}} 1.3$ channels in dorsal horn neurons. This could be tested in future studies by examining the effects of Z123212 on recombinant $\mathrm{Na}_{\mathrm{V}} 1.3$ channels as well as endogenous $\mathrm{Na}_{V}$ currents from rats with enhanced sensitivity to pain.

T-type $\mathrm{Ca}_{V}$ channels are functionally expressed and implicated in modulating the excitability of both DRG and lamina I spinal cord neurons $[20,31,37,39]$. More specifically, $\mathrm{Ca}_{\mathrm{v}} 3.2 \mathrm{~T}$-type channels have been directly linked to hyperalgesia and allodynia in various pain animal models $[1,6,9,21,29]$. We characterized the slow inactivation properties of recombinant $\mathrm{Ca}_{\mathrm{v}} 3.2$ channels for the first time and found properties consistent with those previously described for $\mathrm{Ca}_{\mathrm{V}} 3.1$ channels (Fig. 2C; [17]). Z123212 significantly altered the voltage dependence and extent of $\mathrm{Ca}_{\mathrm{v}} 3.2$ slow inactivation as well as the recovery from slow inactivation (Fig. 2). Given the contributions of $\mathrm{Ca}_{\mathrm{v}} 3.2 \mathrm{~T}$-type channels toward nociceptive signaling, the effects of Z123212 observed on AP firing, hyperalgesia and allodynia may be partly mediated by interactions with $\mathrm{Ca}_{\mathrm{v}} 3.2$ channels. A definitive role for functionally expressed $\mathrm{Ca}_{\mathrm{v}} 3.3$ channels in peripheral and central nociception pathways remains to be elucidated. In contrast, attenuation of central $\mathrm{Ca}_{\mathrm{v}} 3.1$ channel activity has actually been shown to be pronociceptive [23]; thus, in the central nervous system at least Z123212 is unlikely to induce antinociceptive effects through this T-type isoform.

It has been previously shown that $\mathrm{Na}_{\mathrm{V}}$ and $\mathrm{Ca}_{\mathrm{V}}$ currents act synergistically to prolong subthreshold depolarizations within lamina I neurons [35], which may account for the greater effect of Z123212 on lamina I/II neuron excitability compared to its individual effects on specific $\mathrm{Na}_{\mathrm{V}}$ and $\mathrm{Ca}_{\mathrm{V}} 3.2$ channel isoforms. Taken together, we predict that Z123212 exerts its effects on neuronal excitability and nociceptive signaling by enhancing the combined slow inactivation of multiple pronociceptive $\mathrm{Na}_{V}$ and $\mathrm{Ca}_{V}$ channel isoforms.

Z123212 shares some structural features with lacosamide (the dipeptide backbone highlighted in Fig. 1), an antiepileptic drug shown to attenuate chronic pain and enhance slow inactivation of $\mathrm{Na}_{V} 1.3, \mathrm{Na}_{\mathrm{V}} 1.7$, and TTX-resistant DRG $\mathrm{Na}_{V}$ currents [40]. To date, the effects of lacosamide on in situ neuronal firing patterns have only been characterized for cultured neocortical neurons [12]. We find that lacosamide reduces the AP firing of lamina I/II spinal cord neurons at high micromolar concentrations $\left(\mathrm{IC}_{50}=150 \mu \mathrm{M}\right.$; Fig. 7). In the lamina $\mathrm{I} / \mathrm{II}$ neuron preparation, Z123212 inhibits AP firing approximately 300 times more potently than lacosamide $\left(\mathrm{IC}_{50}=0.48 \mu \mathrm{M}\right.$; Fig. 7). The concentration of lacosamide shown to alter neuronal excitability and affect $\mathrm{Na}_{\mathrm{V}}$ channel slow inactivation (predominantly $100 \mu \mathrm{M}$ and above; Suppl. Fig. 6) are generally beyond therapeutic plasma levels achieved by oral dosing $(10-60 \mu \mathrm{M})[4,12,40]$. Of note, a recent study showed that direct systemic injection of lacosamide could reduce evoked dorsal horn neuronal responses in vivo [3]. Lacosamide also binds to the signaling protein collapsin-response mediator protein 2 (affinity $\sim 5 \mu \mathrm{M}$ ) involved in neuroprotection and axonal remodeling, and it is currently unclear whether the effects of lacosamide on $\mathrm{Na}_{V}$ channel slow inactivation are directly linked to its antinociceptive properties [4]. We find that Z123212 reduces lamina I/II neuronal excitability and enhances $\mathrm{Na}_{V}$ channel slow inactivation at concentrations $(1-3 \mu \mathrm{M})$ that are within both therapeutic plasma and brain tissue levels $(10-17 \mu \mathrm{M}$ and $3-5 \mu \mathrm{M}$, respectively). The ability of Z123212 to target multiple mechanistic elements that contribute to neuronal hyperexcitability by stabilizing the slowinactivated state of both $\mathrm{Na}_{V}$ and $\mathrm{Ca}_{V}$ channels might create an additive effect not previously demonstrated for lacosamide.

\subsection{Potential development of novel mixed $\mathrm{Na}_{V} / \mathrm{Ca}_{V}$ channel therapeutics}

We have identified Z123212 as the first dual modulator of $\mathrm{Na}_{\mathrm{V}} /$ $\mathrm{Ca}_{\mathrm{V}}$ channel slow inactivation and have shown that it is efficacious in reversing mechanical and thermal hypersensitivity in animal models of pain. A number of currently marketed therapeutics nonspecifically inhibit T-type $\mathrm{Ca}_{\mathrm{V}}$ channel isoforms (eg, phenytoin and ethosuximide), and mechanistically, blockade occurs through the channel resting state $[2,43]$. These compounds also nonselectively block $\mathrm{Na}_{\mathrm{V}}$ channels and act on other molecular targets $[27,28]$. Z123212 represents a novel class of small organic blocker that acts across the $\mathrm{Na}_{\mathrm{V}}$ and $\mathrm{Ca}_{\mathrm{V}}$ ion channel families but specifically targets the slow-inactivated state. We predict that the specificity for affecting channel slow inactivation could enable the preferential targeting of channels associated with pathophysiological states linked to hyperexcitability (eg, epilepsy and neuropathic pain). In support, although Z123212 also affects $\mathrm{Na}_{\mathrm{V}} 1.5$ and $\mathrm{Ca}_{\mathrm{V}} 1.2$ slow inactivation under certain experimental conditions, we did not find off-target cardiovascular effects in isolated rabbit hearts. Further, we did not observe any adverse effects of high doses of Z123212 in regards to motor coordination. 


\section{Conflict of interest statement}

Zalicus Pharmaceuticals is a subsidiary of Zalicus Inc, Cambridge, MA. Paula Smith, Cyrus Eduljee, Janette Mezeyova, Molly Fee-Maki, Yongbao Zhu, Francesco Belardetti, Hassan Pajouhesh, David Parker, Manjeet Parmar, Elizabeth Tringham, Gerald Zamponi and Terrance P. Snutch all hold shares and/or options in Zalicus Inc.

\section{Acknowledgments}

We thank Drs Peter Smith, Yishen Chen, Patrick Whelan, and Pengcheng Han for training in the spinal cord slice technique. TPS is supported by an operating grant from the Canadian Institutes of Health Research and a Tier 1 Canada Research Chair in Biotechnology and Genomics-Neurobiology. MEH was supported by an Industrial Research and Development Fellowship from the Natural Sciences and Engineering Research Council of Canada. GWZ is a scientist of the Alberta Heritage Foundation for Medical Research and is also supported by a Canada Research Chair in Molecular Neurobiology.

\section{Appendix A. Supplementary data}

Supplementary data associated with this article can be found, in the online version, at doi:10.1016/j.pain.2010.12.035.

\section{References}

[1] Barbara G, Alloui A, Nargeot J, Lory P, Eschalier A, Bourinet E, Chemin J. T-type calcium channel inhibition underlies the analgesic effects of the endogenous lipoamino acids. J Neurosci 2009;29:13106-14.

[2] Barton ME, Eberle EL, Shannon HE. The antihyperalgesic effects of the T-type calcium channel blockers ethosuximide, trimethadione, and mibefradil. Eur J Pharmacol 2005;521:79-85.

[3] Bee LA, Dickenson AH. Effects of lacosamide, a novel sodium channel modulator, on dorsal horn neuronal responses in a rat model of neuropathy. Neuropharmacology 2009;57:472-9.

[4] Beyreuther BK, Freitag J, Heers C, Krebsfanger N, Scharfenecker U, Stohr T. Lacosamide: a review of preclinical properties. CNS Drug Rev 2007;13:21-42.

[5] Blair NT, Bean BP. Role of tetrodotoxin-resistant $\mathrm{Na}^{+}$current slow inactivation in adaptation of action potential firing in small-diameter dorsal root ganglion neurons. J Neurosci 2003;23:10338-50.

[6] Bourinet E, Alloui A, Monteil A, Barrere C, Couette B, Poirot O, Pages A, McRory J, Snutch TP, Eschalier A, Nargeot J. Silencing of the $\mathrm{Ca}_{\mathrm{v}} 3.2$ T-type calcium channel gene in sensory neurons demonstrates its major role in nociception. EMBO J 2005;24:315-24.

[7] Chaplan SR, Bach FW, Pogrel JW, Chung JM, Yaksh TL. Quantitative assessment of tactile allodynia in the rat paw. J Neurosci Methods 1994;53:55-63.

[8] Chen CC, Lamping KG, Nuno DW, Barresi R, Prouty SJ, Lavoie JL, Cribbs LL, England SK, Sigmund CD, Weiss RM, Williamson RA, Hill JA, Campbell KP. Abnormal coronary function in mice deficient in alpha1H T-type $\mathrm{Ca}^{2+}$ channels. Science 2003;302:1416-8.

[9] Choi S, Na HS, Kim J, Lee J, Lee S, Kim D, Park J, Chen CC, Campbell KP, Shin HS Attenuated pain responses in mice lacking $\mathrm{Ca}(\mathrm{V}) 3.2$ T-type channels. Genes Brain Behav 2007;6:425-31.

[10] Cummins TR, Sheets PL, Waxman SG. The roles of sodium channels in nociception: implications for mechanisms of pain. Pain 2007;131:243-57.

[11] Drdla R, Sandkuhler J. Long-term potentiation at C-fibre synapses by low-level presynaptic activity in vivo. Mol Pain 2008;4:18

[12] Errington AC, Stohr T, Heers C, Lees G. The investigational anticonvulsant lacosamide selectively enhances slow inactivation of voltage-gated sodium channels. Mol Pharmacol 2008;73:157-69.

[13] Fukuoka T, Kobayashi K, Noguchi K. Laminae-specific distribution of alphasubunits of voltage-gated sodium channels in the adult rat spinal cord. Neuroscience 2010;169:994-1006.

[14] Hains BC, Klein JP, Saab CY, Craner MJ, Black JA, Waxman SG. Upregulation of sodium channel Nav1.3 and functional involvement in neuronal hyperexcitability associated with central neuropathic pain after spinal cord injury. J Neurosci 2003;23:8881-92.

[15] Hains BC, Saab CY, Klein JP, Craner MJ, Waxman SG. Altered sodium channel expression in second-order spinal sensory neurons contributes to pain after peripheral nerve injury. J Neurosci 2004;24:4832-9.

[16] Hargreaves K, Dubner R, Brown F, Flores C, Joris J. A new and sensitive method for measuring thermal nociception in cutaneous hyperalgesia. Pain $1988 ; 32: 77-88$
[17] Hering J, Feltz A, Lambert RC. Slow inactivation of the $\mathrm{Ca}(\mathrm{V}) 3.1$ isotype of $\mathrm{T}$ type calcium channels. J Physiol 2004:555:331-44.

[18] Hildebrand ME, David LS, Hamid J, Mulatz K, Garcia E, Zamponi GW, Snutch TP. Selective inhibition of Cav3.3 T-type calcium channels by Galphaq/11-coupled muscarinic acetylcholine receptors. J Biol Chem 2007;282:21043-55.

[19] Hildebrand ME, Snutch TP. Contributions of T-type calcium channels to the pathophysiology of pain signaling. Drug Discov Today Dis Mech 2006;3:335-41.

[20] Ikeda H, Heinke B, Ruscheweyh R, Sandkuhler J. Synaptic plasticity in spinal lamina I projection neurons that mediate hyperalgesia. Science 2003;299:1237-40.

[21] Jagodic MM, Pathirathna S, Nelson MT, Mancuso S, Joksovic PM, Rosenberg ER, Bayliss DA, Jevtovic-Todorovic V, Todorovic SM. Cell-specific alterations of Ttype calcium current in painful diabetic neuropathy enhance excitability of sensory neurons. J Neurosci 2007;27:3305-16.

[22] Keller AF, Beggs S, Salter MW, De Koninck Y. Transformation of the output of spinal lamina I neurons after nerve injury and microglia stimulation underlying neuropathic pain. Mol Pain 2007;3:27.

[23] Kim D, Park D, Choi S, Lee S, Sun M, Kim C, Shin HS. Thalamic control of visceral nociception mediated by T-type $\mathrm{Ca}^{2+}$ channels. Science 2003;302:117-9.

[24] Kim SH, Chung JM. An experimental model for peripheral neuropathy produced by segmental spinal nerve ligation in the rat. Pain 1992;50: 355-63.

[25] Laird JM, Souslova V, Wood JN, Cervero F. Deficits in visceral pain and referred hyperalgesia in Nav1.8 (SNS/PN3)-null mice. J Neurosci 2002;22:8352-6.

[26] Latremoliere A, Woolf CJ. Central sensitization: a generator of pain hypersensitivity by central neural plasticity. J Pain 2009;10:895-926.

[27] Leresche N, Parri HR, Erdemli G, Guyon A, Turner JP, Williams SR, Asprodini E, Crunelli V. On the action of the anti-absence drug ethosuximide in the rat and cat thalamus. J Neurosci 1998;18:4842-53.

[28] Meldrum BS, Rogawski MA. Molecular targets for antiepileptic drug development. Neurotherapeutics 2007;4:18-61.

[29] Messinger RB, Naik AK, Jagodic MM, Nelson MT, Lee WY, Choe WJ, Orestes P, Latham JR, Todorovic SM, Jevtovic-Todorovic V. In vivo silencing of the $\mathrm{Ca}(\mathrm{V}) 3.2 \mathrm{~T}$-type calcium channels in sensory neurons alleviates hyperalgesia in rats with streptozocin-induced diabetic neuropathy. Pain 2009;145: 184-95.

[30] Nassar MA, Stirling LC, Forlani G, Baker MD, Matthews EA, Dickenson AH, Wood JN. Nociceptor-specific gene deletion reveals a major role for Nav1.7 (PN1) in acute and inflammatory pain. Proc Natl Acad Sci USA 2004;101:12706-11.

[31] Nelson MT, Joksovic PM, Perez-Reyes E, Todorovic SM. The endogenous redox agent L-cysteine induces $\mathrm{T}$-type $\mathrm{Ca}^{2+}$ channel-dependent sensitization of a novel subpopulation of rat peripheral nociceptors. $J$ Neurosci 2005;25:8766-75.

[32] Pajouhesh H, Feng ZP, Ding Y, Zhang L, Pajouhesh H, Morrison JL, Belardetti F, Tringham E, Simonson E, Vanderah TW, Porreca F, Zamponi GW, Mitscher LA, Snutch TP. Structure-activity relationships of diphenylpiperazine N-type calcium channel inhibitors. Bioorg Med Chem Lett 2010;20:1378-83.

[33] Powell KL, Cain SM, Ng C, Sirdesai S, David LS, Kyi M, Garcia E, Tyson JR, Reid CA, Bahlo M, Foote SJ, Snutch TP, O'Brien TJ. A Cav3.2 T-type calcium channel point mutation has splice-variant-specific effects on function and segregates with seizure expression in a polygenic rat model of absence epilepsy. J Neurosci 2009;29:371-80.

[34] Prescott SA, De Koninck Y. Four cell types with distinctive membrane properties and morphologies in lamina I of the spinal dorsal horn of the adult rat. J Physiol 2002;539:817-36.

[35] Prescott SA, De Koninck Y. Integration time in a subset of spinal lamina I neurons is lengthened by sodium and calcium currents acting synergistically to prolong subthreshold depolarization. J Neurosci 2005;25:4743-54.

[36] Richmond JE, Featherstone DE, Hartmann HA, Ruben PC. Slow inactivation in human cardiac sodium channels. Biophys J 1998;74:2945-52.

[37] Ruscheweyh R, Ikeda H, Heinke B, Sandkuhler J. Distinctive membrane and discharge properties of rat spinal lamina I projection neurones in vitro. J Physiol 2004;555:527-43.

[38] Safronov BV, Wolff M, Vogel W. Functional distribution of three types of $\mathrm{Na}^{+}$ channel on soma and processes of dorsal horn neurones of rat spinal cord. J Physiol 1997;503:371-85.

[39] Scroggs RS, Fox AP. Calcium current variation between acutely isolated adult rat dorsal root ganglion neurons of different size. J Physiol 1992;445:639-58.

[40] Sheets PL, Heers C, Stoehr T, Cummins TR. Differential block of sensory neuronal voltage-gated sodium channels by lacosamide [(2R)-2(acetylamino)- $N$-benzyl-3-methoxypropanamide], lidocaine, and carbamazepine. J Pharmacol Exp Ther 2008;326:89-99.

[41] Suzuki R, Dickenson A. Spinal and supraspinal contributions to central sensitization in peripheral neuropathy. Neurosignals 2005;14:175-81.

[42] Talley EM, Cribbs LL, Lee JH, Daud A, Perez-Reyes E, Bayliss DA. Differential distribution of three members of a gene family encoding low voltage-activated (T-type) calcium channels. J Neurosci 1999;19:1895-911.

[43] Todorovic SM, Perez-Reyes E, Lingle CJ. Anticonvulsants but not general anesthetics have differential blocking effects on different T-type current variants. Mol Pharmacol 2000;58:98-108.

[44] Tripathi PK, Trujillo L, Cardenas CA, Cardenas CG, de Armendi AJ, Scroggs RS. Analysis of the variation in use-dependent inactivation of high-threshold tetrodotoxin-resistant sodium currents recorded from rat sensory neurons. Neuroscience 2006;143:923-38. 
[45] Westenbroek RE, Hoskins L, Catterall WA. Localization of $\mathrm{Ca}^{2+}$ channel subtypes on rat spinal motor neurons, interneurons, and nerve terminals. J Neurosci 1998;18:6319-30.

[46] Woolf CJ, Salter MW. Neuronal plasticity: increasing the gain in pain. Science 2000;288:1765-9.
[47] Zamponi GW, Feng ZP, Zhang L, Pajouhesh H, Ding Y, Belardetti F, Pajouhesh H, Dolphin D, Mitscher LA, Snutch TP. Scaffold-based design and synthesis of potent N-type calcium channel blockers. Bioorg Med Chem Lett 2009;19:6467-72.

[48] Zeilhofer HU. The glycinergic control of spinal pain processing. Cell Mol Life Sci 2005;62:2027-35. 